Utah State University

DigitalCommons@USU

T.W. "Doc" Daniel Experimental Forest

Quinney Natural Resources Research Library,

S.J. and Jessie E.

$1-4-2013$

\title{
Testing Above- and Below-Canopy Representations of Turbulent Fluxes in an Energy Balance Snowmelt Model
}

Vinod Mahat

Utah State University

David G. Tarboton

Utah State University

Noah P. Molotch

University of Colorado at Boulder

Follow this and additional works at: https://digitalcommons.usu.edu/docdan

Part of the Civil and Environmental Engineering Commons

\section{Recommended Citation}

Mahat, V., Tarboton, D. G., and Molotch, N. P. ( 2013), Testing above- and below-canopy representations of turbulent fluxes in an energy balance snowmelt model, Water Resour. Res., 49, doi:10.1002/wrcr.20073.

This Article is brought to you for free and open access by the Quinney Natural Resources Research Library, S.J. and Jessie E. at DigitalCommons@USU. It has been accepted for inclusion in T.W. "Doc" Daniel Experimental Forest by an authorized administrator of DigitalCommons@USU.

For more information, please contact

digitalcommons@usu.edu.

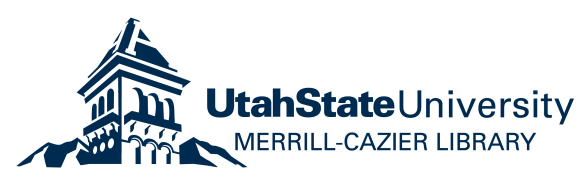




\title{
Testing above- and below-canopy representations of turbulent fluxes in an energy balance snowmelt model
}

\author{
Vinod Mahat, ${ }^{1}$ David G. Tarboton, ${ }^{1}$ and Noah P. Molotch ${ }^{2}$ \\ Received 28 November 2011; revised 4 December 2012; accepted 20 December 2012; published 6 February 2013.
}

[1] Turbulent fluxes of sensible and latent heat are important processes in the surface energy balance that drives snowmelt. Modeling these fluxes in a forested environment is complicated because of the canopy effects on the wind field. This paper presents and tests a turbulent flux model developed to represent these processes in an energy balance snowmelt model. The goal is to model these processes using the readily available inputs of canopy height and leaf area index in a way that minimizes the number of parameters, state variables, and assumptions about hard to quantify processes. Selected periods from 9 years of eddy-covariance (EC) measurements at Niwot Ridge, Colorado, were used to evaluate the effectiveness of this modeling approach. The model was able to reproduce the abovecanopy sensible and latent heat fluxes reasonably with the correlation higher for sensible heat than latent heat. The modeled values of the below-canopy latent heat fluxes also matched the EC-measured values. The model captured the nighttime below-canopy sensible heat flux quite well, but there were discrepancies in daytime sensible heat flux possibly due to mountain slope circulation not quantifiable in this kind of model. Despite the uncertainties in the below-canopy sensible heat fluxes, the results are encouraging and suggest that reasonable predictions of turbulent flux energy exchanges and subsequent vapor losses from snow in forested environments can be obtained with a parsimonious single-layer representation of the canopy. The model contributes an improved physically based capability for predicting the snow accumulation and melt in a forested environment.

Citation: Mahat, V., D. G. Tarboton, and N. P. Molotch (2013), Testing above- and below-canopy representations of turbulent fluxes in an energy balance snowmelt model, Water Resour. Res., 49, doi:10.1002/wrcr.20073.

\section{Introduction}

[2] Turbulent fluxes of heat and water vapor play an important role in snow surface energy and mass balances. The forest canopy strongly influences these fluxes and impacts the energy balance that drives snowmelt and the partitioning of the snow between the sublimation and the runoff in a forested environment. A number of previous studies focused on snow-vegetation interactions have indicated the importance of radiation and turbulent fluxes in snow cover mass and energy balances [e.g., Bartlett et al., 2006; Ellis and Pomeroy, 2007; Ellis et al., 2010; Essery et al., 2003; Koivusalo, 2002; Link and Marks, 1999; Pearson et al., 1999; Tribbeck et al., 2004]. The forest canopy also partitions snowfall and rainfall into

Additional Supporting Information may be found in the online version of this article.

${ }^{1}$ Department of Civil and Environmental Engineering, Utah Water Research Laboratory, Utah State University, Logan, Utah, USA.

${ }^{2}$ Department of Geography and Institute of Arctic and Alpine Research, University of Colorado at Boulder, Boulder, Colorado, USA.

Corresponding author: D. G. Tarboton, Department of Civil and Environmental Engineering, Utah Water Research Laboratory, Utah State University, 4110 Old Main Hill, Logan, UT 84322-4110, USA. (dtarb@usu.edu)

C2013. American Geophysical Union. All Rights Reserved. 0043-1397/13/10.1002/wrcr.20073 interception by the canopy and throughfall to the ground [Hedstrom and Pomeroy, 1998]. The intercepted snow may sublimate, reducing the amount of snow available below the canopy [Lundberg and Halldin, 1994; Lundberg et al., 1998].

[3] Commonly used snowmelt models have been built to operate primarily in open areas where no forest canopy is present [e.g., Anderson, 1976; Jordan, 1991; Marks, 1988; Price, 1988; Price et al., 1976; Tarboton and Luce, 1996]. These models treat the canopy and the underlying surface as a single interface, ignoring the separate turbulent exchange of heat and water vapor between the vegetation canopy and the atmosphere. To model the snow accumulation and melt processes in forested environments, the accurate characterization of turbulent fluxes above, within, and below the canopy is important. A number of snow studies have addressed the representation of the canopy and the surface as separate layers, with canopy temperature assumed to be equal to air temperature [e.g., Ellis et al., 2010; Gelfan et al., 2004; Hellstrom, 2000; Koivusalo, 2002; Storck, 2000]. This assumption may lead to uncertainty in partitioning of energy fluxes between the canopy and the surface, as the canopy temperature controls the canopy longwave radiation emission, suggesting that calculation of both the canopy and surface temperatures may be required. Some detailed hydrological models like Distributed Hydrology Soil Vegetation Model (DHSVM) [Wigmosta et al., 1994, 2002] and Variable Infiltration Capacity (VIC) [Andreadis et al., 2009; 
Cherkauer et al., 2003] consider the canopy and surface temperatures separately in ways similar to the approach here, but we are not aware of detailed evaluations of these representations in comparison to flux measurements.

[4] This study presents and tests the turbulent flux components developed to represent the exchanges of sensible and latent heat among the surface, the canopy, and the atmosphere in a forested environment for an energy balance snowmelt model. This study focuses on the modeling of the below-canopy wind, the turbulent energy fluxes, and the subsequent vapor losses from the snow above and below the canopy and evaluates them in comparison to the observations with an objective of improving the snowmelt modeling capability in heterogeneous watersheds that include forested areas. The model provides a physically based representation of turbulent energy flux transfer through forest canopies based on the practically available information. It uses physically realistic representations of the processes involved while keeping the number of model parameters small so as to be easy to apply in a spatially distributed fashion and so as to be transferable, with limited calibration, to other locations.

[5] A number of land surface models, not specific to a snow environment, have been developed to estimate the turbulent transport of heat and water vapor among the surface, the vegetation canopy, and the atmosphere. These include models with one or more vegetation layers [e.g., Bonan, 1991; Choudhury and Monteith, 1988; Shuttleworth and Wallace, 1985]. In two-layer models, the model is comprised of a ground surface and a single vegetation canopy layer [Inclan and Forkel, 1995], while in multiple layer models vegetation is split into several layers, and the energy balance is solved for each layer in order to describe the heat and water vapor transport processes among different canopy components: roots, stems, leaves, and air around [Demarty et al., 2002]. The model developed here draws upon the concepts from detailed land surface models [e.g., Bonan, 1991; Inclan and Forkel, 1995; Sellers et al., 1986] but with simplifications to avoid dependence on detailed canopy information not commonly available. While multiple layer approaches represent a promising line of investigation, for reasons of simplicity and parsimony this study evaluates a single-layer canopy model.

[6] A single forest canopy layer component was added to the single-layer Utah Energy Balance (UEB) snowmelt model [Tarboton and Luce, 1996; Tarboton et al., 1995]. The resulting model was initially applied at the T.W. Daniel Experimental Forest (TWDEF) site in Utah with adjustable parameters estimated to match measurements at that location. Mahat and Tarboton [2012] evaluated the model's radiation component and compared the measured and modeled snow water equivalent as an evaluation of the model overall. In this paper the model has been transferred and applied to Niwot Ridge, Colorado, for the evaluation of the flux components using data from a separate location, and to take advantage of the eddy-covariance (EC) measurements available at Niwot Ridge. The majority of parameters were transferred directly or estimated from the physical properties of the forest at Niwot Ridge, with only the wind decay coefficient $n$ and surface roughness length $z_{o s}$ parameters adjusted to match the measurements. The parameter $n$ was allowed to vary between canopies while $z_{o s}$ was held constant across all canopies. Evaluation of the interception component will be the subject of a future paper. The layout of this paper is as follows: section 2 describes the field measurements at the two sites, Niwot Ridge and TWDEF. Section 3 describes the flux components of the enhanced model that includes the canopy layer. Section 4 describes the EC flux measurements made at Niwot Ridge used to evaluate the model. Section 5 evaluates the model comparing the simulated and observed wind, energy fluxes, and sublimation. This section includes an analysis of parameter sensitivity. Section 6 is the discussion, and finally section 7 gives the summary and conclusions from this study.

\section{Study Sites and Measurements}

\subsection{Niwot Ridge AmeriFlux Study Site}

[7] The Niwot Ridge AmeriFlux site is located at an elevation of $3050 \mathrm{~m}$ in the Rocky Mountains of Colorado $\left(40^{\circ} 1^{\prime} 58^{\prime \prime} \mathrm{N}\right.$; $\left.105^{\circ} 32^{\prime} 47^{\prime \prime} \mathrm{W}\right)$ approximately $50 \mathrm{~km}$ northwest of Denver. The forest surrounding the flux tower is dominated by subalpine fir (Abies lasiocarpa), Engelmann spruce (Picea engelmannii), and lodgepole pine (Pinus contorta) [Molotch et al., 2007]. The leaf area index is $4.2 \mathrm{~m}^{2} \mathrm{~m}^{-2}$ with a canopy height averaging $11.4 \mathrm{~m}$ and gap fraction of $17 \%$. The forest slopes gently $(6 \%-7 \%)$ and uniformly with elevation increasing from east to west. Average annual precipitation is about $800 \mathrm{~mm}$, of which about $80 \%$ is snow [Caine, 1995]. The dominant wind is from the west, particularly in the winter when periods of high wind speed and neutral atmospheric stability conditions are frequent [Turnipseed et al., 2002].

[8] The above- and below-canopy EC systems were mounted at heights of 21.5 and $1.7 \mathrm{~m}$ above the ground, respectively, on two towers $20 \mathrm{~m}$ apart. The EC systems consisted of 3-D sonic anemometer (CSAT-3, Campbell Scientific, Logan, UT, USA) to measure the wind vector $(\mathbf{u}, \mathbf{v}, \mathbf{w})$ and air temperature, and an infrared gas analyzer (IRGA-6260, LI-COR, Lincoln, NE, USA) to measure water vapor and carbon flux at $10 \mathrm{~Hz}$. Precipitation was measured with a rain and snow gage (Met One 385-L, Campbell Scientific, Logan, UT) at a height of $12 \mathrm{~m}$ on the above-canopy EC tower. To improve the precipitation gauge catch efficiency; an Alter gauge shield was used [Yang et al., 1998]. The meteorological measurements taken at this site include air temperature (CSAT-3, Campbell Scientific, Logan, UT, USA) and wind (Propvane-09101, RM Young, Traverse City, MI, USA) at heights of 21.5 and $1.7 \mathrm{~m}$, respectively, and relative humidity (HMP-35D, Vaisala, Vantaa, Finland) at a height of $21.5 \mathrm{~m}$ above the ground surface. Ground heat flux (REBS HFT-1, Campbell Scientific, Logan, UT, USA) was measured at about $10 \mathrm{~cm}$ below the ground surface. Additional details of instrumentation and further site information including a location map are given by Molotch et al. [2007].

\subsection{TWDEF Site}

[9] The TWDEF site is located at an elevation of $2700 \mathrm{~m}$, about 30 miles northeast of Logan, Utah $\left(41.86^{\circ} \mathrm{N} ; 111.50^{\circ} \mathrm{W}\right)$. Average annual precipitation is about $950 \mathrm{~mm}$ of which about $80 \%$ is snow. Vegetation is classified into deciduous forest (Aspen), coniferous forest (Engelmann spruce and subalpine fir), open meadows consisting of a mixture of grasses and forbs, and shrub areas dominated by sagebrush. Temperature and humidity 
(HMP-50, Vaisala, Vantaa, Finland), wind (Met One 014A, Campbell Scientific, Logan, UT, USA), and net radiation (NR-Lite, Kipp \& Zonen, Delft, Netherlands) are continuously measured in each of the four vegetation classes at this site. Instruments are placed at heights above the ground of about $2.5 \mathrm{~m}$ in conifer, $4.5 \mathrm{~m}$ in deciduous, and $4 \mathrm{~m}$ in shrub and grass classes. Since the TWDEF site does not have EC measurements in forest locations, only the wind components of the turbulent flux model were tested at this site. At the TWDEF measurements of snow depth, density and hence water equivalent are available in the open as well as deciduous and coniferous forest classes. These provide the capability to evaluate the model's overall ability to simulate snow water equivalent accumulation and ablation. Additional details of instrumentation and further site information including a location map are given by Mahat and Tarboton [2012].

\section{Model Description}

[10] The UEB snowmelt model [Tarboton and Luce, 1996] is a physically based point energy and mass balance model for snow accumulation and melt. Snowpack is characterized using three state variables, namely, snow water equivalent $W_{s}(\mathrm{~m})$, the internal energy of the snowpack and top layer of soil $U_{s}\left(\mathrm{~kJ} \mathrm{~m}^{-2}\right)$, and the dimensionless age of the snow surface used for albedo calculations. The UEB model is a single-layer model. $U_{s}$ and $W_{s}$ are predicted at each time step based on the energy balance. The details of the original and other aspects of the enhanced UEB model are given by Tarboton et al. [1995], Tarboton and Luce [1996], You [2004], and Mahat and Tarboton [2012].

[11] In this paper a canopy layer has been added to UEB to parameterize the below-canopy wind and atmospheric transport of heat and water vapor in the forested environment. The model is now a two-layer model that represents the snow on the ground surface and the intercepted snow held in the canopy separately. The temperature of the canopy is taken to be the same as the temperature of intercepted snow in the canopy, and we refer to this as the canopy temperature. The quantity and state of snow in the canopy is represented by a new state variable, canopy snow water equivalent $W_{c}(\mathrm{~m})$. The energy content of intercepted snow in the canopy is assumed to be negligible, and canopy temperature is assumed to adjust to maintain energy equilibrium. Energy balances are solved for each layer to provide outputs of the surface temperature and the canopy temperature based on which the above- and below-canopy turbulent fluxes are computed. When canopy temperature obtained from canopy energy equilibrium is greater than freezing, and snow is present in the canopy, the canopy temperature is set to freezing, and the extra energy drives the melting of snow in the canopy.

[12] In the enhanced UEB the changes with time of state variables $U_{s}, W_{s}$, and $W_{c}$ are determined by the following three equations:

$$
\begin{gathered}
\frac{\mathrm{d} U_{s}}{\mathrm{~d} t}=Q_{s i}+Q_{g}-Q_{m s} \\
\frac{\mathrm{d} W_{s}}{\mathrm{~d} t}=P_{r}+P_{s}-i+R_{m}+M_{c}-E_{s}-M_{s}, \\
\frac{\mathrm{d} W_{c}}{\mathrm{~d} t}=i-R_{m}-M_{c}-E_{c}
\end{gathered}
$$

where energy fluxes are combined surface energy input $Q_{s i}$, ground heat flux $Q_{g}$, and advected heat removed by melt water $Q_{m s}$. Mass fluxes are: rainfall $P_{r}$, snowfall $P_{s}$, canopy interception $i$, mass release from the canopy $R_{m}$, melt water drip from the canopy snow $M_{c}$, melt from the surface snow $M_{s}$, sublimation from the canopy snow $E_{c}$, and sublimation from the surface snow $E_{s}$. Terms in the energy balance equation are expressed per unit of horizontal area in $\mathrm{kJ} \mathrm{m}^{-2}$ $\mathrm{h}^{-1}$. Terms in the mass balance equations are expressed in $\mathrm{m} \mathrm{h}^{-1}$.

[13] The combined surface energy input is given by

$$
Q_{s i}=Q_{s n s}+Q_{s n l}+Q_{p s}+Q_{h s}+Q_{e s},
$$

where $Q_{s n s}$ is the below-canopy net shortwave radiation, $Q_{s n l}$ is the below-canopy net longwave radiation, $Q_{p s}$ is the advected heat from precipitation, $Q_{h s}$ is the sensible heat flux, and $Q_{e s}$ is the latent heat flux due to sublimation/ condensation.

[14] Energy content of the intercepted snow is considered negligible. To reflect this, the canopy energy balance is written as

$$
Q_{c n s}+Q_{c n l}+Q_{p c}+Q_{h c}+Q_{e c}-Q_{m c}=0,
$$

where $Q_{c n s}$ is the canopy net shortwave radiation, $Q_{c n l}$ is the canopy net longwave radiation, $Q_{p c}$ is the net advected heat from precipitation to the canopy, $Q_{h c}$ is the sensible heat to the canopy, $Q_{e c}$ is the latent heat to the canopy, and $Q_{m c}$ is the advected heat removed by melt water from the canopy.

[15] In equations (4) and (5), $Q_{s n l}, Q_{h s}, Q_{e s}, Q_{c n l}, Q_{h c}$, and $Q_{e c}$ are the functions of the surface and canopy temperatures $T_{s}$ and $T_{c}$, as well as inputs that drive the model. In the case of the longwave radiation terms $Q_{s n l}$ and $Q_{c n l}$, this functionality is based on the Stefan-Boltzmann equation for longwave radiation and the model for the transmission of radiation through and the emission of radiation by the canopy described by Mahat and Tarboton [2012]. Expressions for the turbulent flux quantities $Q_{h s}, Q_{e s}, Q_{h c}$, and $Q_{e c}$ are developed below. UEB uses the modified Force-Restore approach [Luce and Tarboton, 2010] to equate $Q_{s i}$ in equation (4) to conduction into the snow as a function of $T_{s}$, its past values, and the average temperature of the snow. UEB evaluates the snow surface temperature separately from the average temperature of the snowpack reflected by the snow pack energy content [Luce and Tarboton, 2010; You, 2004]. In solving the model at each time step, $Q_{m c}$ is initially set to 0 . The result is two nonlinear equations (4) and (5) that depend only on the unknowns $T_{c}$ and $T_{s}$. These simultaneous equations are solved using the NewtonRaphson iterative method. In the event that $T_{c}$ is above freezing, and there is intercepted snow in the canopy $\left(W_{c}>0\right), T_{c}$ is set to 0 , and equation (5) is used to evaluate $Q_{m c}$. In the event that $T_{s}$ is above freezing, and there is snow on the ground ( $\left.W_{s}>0\right), Q_{s i}$ is evaluated with $T_{s}$ set to freezing. The resulting extra surface energy above that conducted into the snow calculated using the Force-Restore approach is used to calculate the amount of melt generated at the surface. This melt infiltrates into the snowpack, and the energy is added to $U_{s}$ during the solution of equations (1)-(3), which are advanced through time using a 


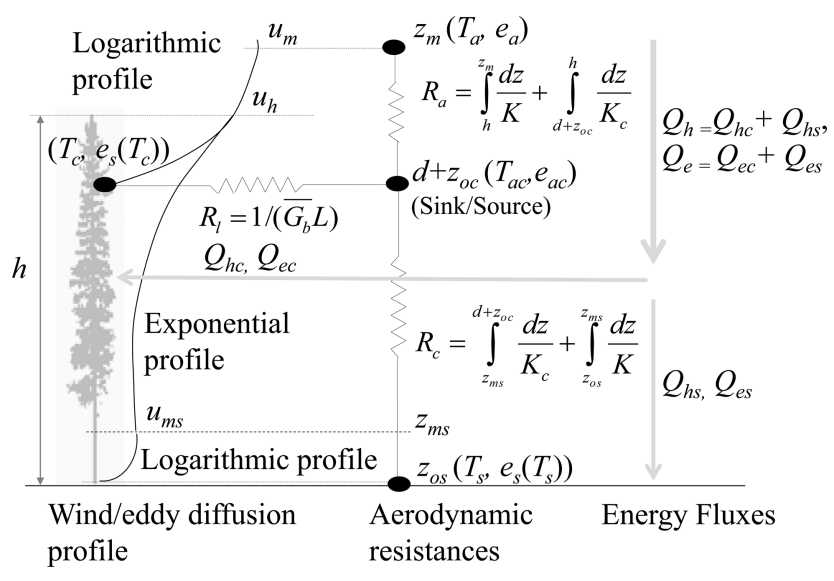

Figure 1. Schematic of wind/eddy diffusion profiles, below- and above-canopy aerodynamic resistances, canopy boundary layer resistance, and energy exchange among snow at the surface, in the canopy and the atmosphere.

predictor-corrector approach [Gerald, 1978; Tarboton et al., 1995].

\subsection{Turbulent Energy Fluxes}

[16] The main structure of the flux model and the basic equations used here are similar to those originally given by Norman et al. [1995] in their series network two-layer flux model. A similar approach has also been used in a number of other studies [e.g., Andreadis et al., 2009; Bonan, 1991; Inclan and Forkel, 1995; Sellers et al., 1986]. This approach uses the temperature and vapor pressure differences among the snow surface, canopy air, and snow in the canopy to calculate the turbulent flux exchanges among the snow on the ground, the canopy, and the atmosphere (Figure 1).

$$
\begin{gathered}
Q_{h}=\frac{\rho_{a} C_{p}\left(T_{a}-T_{a c}\right)}{R_{a}}, \\
Q_{h s}=\frac{\rho_{a} C_{p}\left(T_{a c}-T_{s}\right)}{R_{c}}, \\
Q_{h c}=\frac{\rho_{a} C_{p}\left(T_{a c}-T_{c}\right)}{R_{l}}, \\
Q_{e}=\frac{1}{R_{a}} \frac{h_{v} 0.622}{R_{d} T_{a c}}\left(e_{a}-e_{a c}\right), \\
Q_{e s}=\frac{1}{R_{c}} \frac{h_{v} 0.622}{R_{d} T_{a c}}\left(\left(e_{a c}-e_{s}\left(T_{s}\right)\right),\right. \\
Q_{e c}=\frac{1}{R_{l}} \frac{h_{v} 0.622}{R_{d} T_{a c}}\left(e_{a c}-e_{s}\left(T_{c}\right)\right),
\end{gathered}
$$

where $Q_{h}$ and $Q_{e}$ are the total fluxes of sensible heat and latent heat from the atmosphere which are partitioned into $Q_{h c}$ and $Q_{e c}$, the sensible and latent heat flux contributions to the forest canopy, and $Q_{h s}$ and $Q_{e s}$, the sensible and latent heat flux contributions to the surface. In these equations $R_{a}$ and $R_{c}$ are the aerodynamic resistances to heat and vapor transport between the air in the canopy and air above and between the snow surface and the air in the canopy, respectively $\left(\mathrm{h} \mathrm{m}^{-1}\right)$, and $R_{l}$ is the bulk leaf boundary layer resistance $\left(\mathrm{h} \mathrm{m}^{-1}\right)$. These resistances are discussed in detail in the subsequent sections. $T_{a c}$ is the canopy air temperature $\left({ }^{\circ} \mathrm{C}\right), T_{s}$ is the surface temperature $\left({ }^{\circ} \mathrm{C}\right), T_{c}$ is the canopy temperature $\left({ }^{\circ} \mathrm{C}\right), T_{a}$ is the above-canopy air temperature $\left({ }^{\circ} \mathrm{C}\right), e_{a c}$ is the canopy air vapor pressure $(\mathrm{Pa}), e_{a}$ is the above-canopy air vapor pressure $(\mathrm{Pa})$, and $e_{s}\left(T_{s}\right)$ and $e_{s}\left(T_{c}\right)$ are the surface and canopy saturated vapor pressures calculated as functions of snow and canopy temperatures, respectively. Standard formulae for saturation vapor pressure over ice are used when the temperature is below freezing [Lowe, 1977]. $\rho_{a}$ is the air density, $C_{p}$ is the specific heat capacity of air $\left(1.005 \mathrm{~kJ} \mathrm{~kg}^{-1}{ }^{\circ} \mathrm{C}^{-1}\right), h_{\nu}$ is the latent heat of sublimation $\left(2834 \mathrm{~kJ} \mathrm{~kg}^{-1}\right)$, and $R_{d}$ is the dry gas constant $\left(287 \mathrm{~J} \mathrm{~kg}^{-1} \mathrm{~K}^{-1}\right)$. The partitioning of $Q_{h}$ and $Q_{e}$ into $Q_{h c}, Q_{e c}, Q_{h s}$, and $Q_{e s}$ is given by

$$
\begin{aligned}
& Q_{h}=Q_{h c}+Q_{h s}, \\
& Q_{e}=Q_{e c}+Q_{e s} .
\end{aligned}
$$

[17] These equations facilitate the evaluation of $T_{a c}$ and $e_{a c}$ as functions of $T_{a}, T_{s}, T_{c}, e_{a}$, and the saturated vapor pressures $e_{s}\left(T_{s}\right)$ and $e_{s}\left(T_{c}\right)$.

$$
\begin{gathered}
T_{a c}=\left(\frac{T_{c}}{R_{l}}+\frac{T_{s}}{R_{c}}+\frac{T_{a}}{R_{a}}\right) /\left(\frac{1}{R_{l}}+\frac{1}{R_{c}}+\frac{1}{R_{a}}\right), \\
e_{a c}=\left(\frac{e_{s}\left(T_{c}\right)}{R_{l}}+\frac{e_{s}\left(T_{s}\right)}{R_{c}}+\frac{e_{a}}{R_{a}}\right) /\left(\frac{1}{R_{l}}+\frac{1}{R_{c}}+\frac{1}{R_{a}}\right) .
\end{gathered}
$$

[18] Substitution of equations (14) and (15) in equations (7), (8), (10), and (11) results in expressions for $Q_{h c}, Q_{e c}$, $Q_{h s}$, and $Q_{e s}$, which are functions only of the inputs and two unknowns $T_{c}$ and $T_{s}$ and of the resistances discussed below. Substituting these into equations (4) and (5) results in all terms on the right of equation (4) and all terms except for $Q_{m c}$ in equation (5) being expressed in terms of $T_{c}$ and $T_{S}$ as required for their solution as described above, with $Q_{m c}$ initially being set to 0 . In the event that the resultant $T_{c}$ is above freezing and there is intercepted snow in the canopy, $T_{c}$ is set to 0 , and $Q_{m c}$ is evaluated from (5).

\subsubsection{Wind Profile and Aerodynamic Resistances}

[19] The wind profile is assumed to be logarithmic above the canopy $z \geq h$, exponential within the canopy $\left(z_{m s} \leq z<h\right)$, and again logarithmic over the snow surface on the ground $\left(z<z_{m s}\right)$ as are typical in the literature [e.g., Bonan, 1991; Cionco, 1972; Dolman, 1993; Koivusalo, 2002] (Figure 1). Here $z$ is the height above the ground or snow surface, $z_{m s}$ is the reference height above the surface, where the profile is assumed to switch from logarithmic to exponential (taken as $2 \mathrm{~m}$ here), and $h$ is the canopy height. The logarithmic and exponential wind profiles [Bonan, 1991; Brutsaert, 1982] are

$$
\begin{gathered}
u(z)=\frac{1}{k} u * \ln \left(\frac{z-d}{z_{o}}\right) \quad \text { for } z \geq h \text { and } z<z_{m s}, \\
u(z)=u_{h} \exp [-n(1-z / h)] \quad \text { for } z_{m s} \leq z<h,
\end{gathered}
$$

where $u(z)$ is the wind speed at height $z, u_{h}$ is the wind speed at canopy height $h, n$ is an exponential decay 
coefficient, $d$ is the zero-plane displacement height, and $z_{o}$ is the roughness length. $u^{*}$ is the shear (friction) velocity, and $k$ is von Karman's constant $(k=0.4)$. The above-canopy wind speed $u_{m}$ measured at height $z_{m}(>h)$ above the ground is taken as input, and the model calculates the wind profile working downward from the top (see Figure 1). Equation (16) is applied with different $d, z_{o}$, and $u^{*}$ above the canopy $(z \geq h)$ and for the near-surface boundary layer $\left(z<z_{m s}\right) . z_{o}$ is equal to $z_{o c}$ (roughness length for the top of the canopy boundary layer) for $z \geq h$ and $z_{o s}$ (snow surface roughness length) for $z<z_{m s}$. For the surface logarithmic profile layer $\left(z<z_{m s}\right), d$ is taken as 0 . For the canopy logarithmic profile layer $(z \geq h), d$ and $z_{o c}$ are estimated as functions of tree height $(h)$, tree profile shape, and leaf area index $(L)$ following Shaw and Pereira [1982] as

$$
\begin{gathered}
d=h\left(0.05+\frac{L^{0.02}}{2}+\frac{(y-1)}{20}\right), \\
z_{o c}=h\left(0.23-\frac{L^{0.25}}{10}-\frac{(y-1)}{67}\right),
\end{gathered}
$$

where $y$ is an integer indicating one of the three basic forest profiles [e.g., Massman, 1982; Meyers et al., 1998]: $y=1$ for young pine, $y=2$ for leafed deciduous tree, and $y=3$ for old pine with long stems and clumping at the top.

[20] Aerodynamic resistances $R_{a}$ and $R_{c}$ are calculated based on the K-theory [Choudhury and Monteith, 1988; Demarty et al., 2002; Dolman, 1993; Inclan and Forkel, 1995; Koivusalo, 2002; Shuttleworth and Gurney, 1990]. The above-canopy aerodynamic resistance $R_{a}$ (for $\left.d+z_{o c}<z<z_{m}\right)$ and the below-canopy aerodynamic resistance $R_{c n}$ (for $z_{o s}<z<d+z_{o c}$ ) for neutral atmospheric conditions are calculated as

$$
\begin{aligned}
& R_{a}=\int_{h}^{z_{m}} \frac{\mathrm{d} z}{K}+\int_{d+z_{o c}}^{h} \frac{\mathrm{d} z}{K_{c}}, \\
& R_{c n}=\int_{z_{m s}}^{d+z_{o c}} \frac{\mathrm{d} z}{K_{c}}+\int_{z_{o s}}^{z_{m s}} \frac{\mathrm{d} z}{K} .
\end{aligned}
$$

[21] Here $K$ and $K_{c}$ are the eddy diffusion coefficients that correspond to the logarithmic and exponential wind profiles, respectively. These coefficients are given by [Dolman, 1993]

$$
\begin{gathered}
K=k u^{*}(z-d) \sqrt{(1-\mathrm{z} / \mathrm{h})} \\
K_{c}=K_{h} \exp \left[-n\left(\frac{1-z}{h}\right)\right],
\end{gathered}
$$

where $K_{h}$ is the eddy diffusion coefficient $K$ for the canopy evaluated at height $h$. Its value for the input $u=u_{m}$ at height $z_{m}$ is determined as

$$
K_{h}=\frac{k^{2} u_{m}(h-d)}{\ln \left(\frac{z_{m}-d}{z_{o c}}\right)} .
$$

[22] Substituting the values of $K$ and $K_{c}$ and integrating equations (20) and (21) yields

$$
\begin{aligned}
& R_{a}= \frac{1}{k^{2} u_{m}} \ln \left(\frac{z_{m}-d}{z_{o c}}\right) \ln \left(\frac{z_{m}-d}{h-d}\right) \\
&+ \frac{h}{K_{h} n}\left\{\exp \left[n-n\left(\frac{d+z_{o c}}{h}\right)\right]-1\right\}, \\
& R_{c n}= \frac{h \exp (n)}{K_{h} n}\left\{\exp \left[-n\left(\frac{z_{m s}}{h}\right)\right]-\exp \left[-n\left(\frac{d+z_{o c}}{h}\right)\right]\right\} \\
&+\frac{1}{k^{2} u_{m s}} \ln \left(\frac{z_{m s}}{z_{o s}}\right)^{2} .
\end{aligned}
$$

[23] Atmospheric stability adjustments to turbulent fluxes use the expressions suggested by Choudhury and Monteith [1988].

$$
\begin{gathered}
R_{c}=\frac{R_{c n}}{\left(1-5 R_{i}\right)^{2}} \quad \text { stable } \quad 0<R_{i} \leq R_{i \max }, \\
R_{c}=\frac{R_{c n}}{\left(1-5 R_{i}\right)^{3 / 4}} \quad \text { unstable } \quad R_{i}<0, \\
R_{i}=\frac{g\left(T_{a}-T_{s}\right) z_{m s}}{u_{m s}^{2}\left[0.5\left(T_{a}+T_{s}\right)+273.15\right]},
\end{gathered}
$$

where $R_{i}$ is an estimate of the Richardson number, $R_{i \max }$ is the upper limit of the Richardson number taken as 0.16 (Table 1) [Choudhury and Monteith, 1988; Koivusalo, 2002], and $g$ is the acceleration due to gravity. Note that in earlier implementations of UEB [Tarboton and Luce, 1996] a parameter had been included to switch off the stability adjustments. In the present implementation this parameter has been deactivated, and all results here use the stability adjustments. The fact that the model is working satisfactorily with these stability corrections is pleasing from a theoretical perspective, as there was no physical theoretical basis for switching off the stability adjustments in the previous work.

[24] Note that the inputs to the evaluation of aerodynamic resistances as detailed above are the parameters $z_{m s}$, $z_{o s}$, and $R_{i \max }$ (Table 1 ) and the site variables canopy height $h$, leaf area index $L$, tree profile shape parameter $y$, and wind decay coefficient $n$, (Table 2). Time varying inputs are the wind speed above the canopy $u_{m}$ at height $z_{m}$, canopy air temperature $T_{a}$, and surface temperature $T_{s}$ that are determined during the solution (section 3.1).

\subsubsection{Leaf Boundary Layer Resistance}

[25] Bulk leaf boundary layer resistance is calculated based on the wind, leaf dimension, and leaf area distribution. Following Jones [1992] leaf boundary layer conductance, which is the reciprocal of the leaf boundary layer resistance, is

$$
G_{b}(z) \approx 0.01 \sqrt{u(z) / w},
$$

where $G_{b}(z)$ is the boundary layer conductance $\left(\mathrm{m} \mathrm{s}^{-1}\right)$ for a unit projected area of a leaf, $w$ is the leaf width (m), and $u(z)$ is the wind speed $\left(\mathrm{m} \mathrm{s}^{-1}\right)$ at height $z$. Bonan [1991] and Dickinson et al. [1986] suggested a fixed value of 0.04 $\mathrm{m}$ for $w$ that was used as a constant here.

[26] Assuming leaf area is uniformly distributed with the tree height, the mean leaf conductance is obtained [Choudhury and Monteith, 1988] as 
Table 1. Model Parameters

\begin{tabular}{|c|c|c|}
\hline Name & Values & Basis \\
\hline Air temperature above which precipitation is all rain $\left(T_{r}\right)$ & $3^{\circ} \mathrm{C}$ & Tarboton et al. [1995], U.S. Army Corps of Engineers [1956] \\
\hline Air temperature below which precipitation is all snow $\left(T_{s n}\right)$ & $-1^{\circ} \mathrm{C}$ & Tarboton et al. [1995], U.S. Army Corps of Engineers [1956] \\
\hline Emissivity of snow $\left(\varepsilon_{s}\right)$ & 0.98 & Tarboton et al. [1995] \\
\hline Ground heat capacity $\left(C_{g}\right)$ & $2.09 \mathrm{~kJ} \mathrm{~kg}^{-1} \mathrm{C}^{-1}$ & Tarboton et al. [1995] \\
\hline $\begin{array}{l}\text { Nominal measurement of height for air temperature and } \\
\text { humidity }\left(z_{m s}\right)\end{array}$ & $2.0 \mathrm{~m}$ & Tarboton et al. [1995] \\
\hline Surface aerodynamic roughness $\left(z_{o s}\right)$ & $0.1 \mathrm{~m}$ & Adjusted from previous open area value of $0.01 \mathrm{~m}$ \\
\hline Soil density $\left(\rho_{g}\right)$ & $1700 \mathrm{~kg} \mathrm{~m}^{-3}$ & Tarboton et al. [1995] \\
\hline Liquid holding capacity of snow $\left(L_{c}\right)$ & 0.05 & Tarboton et al. [1995] \\
\hline Snow saturated hydraulic conductivity $\left(K_{s}\right)$ & $20 \mathrm{~m} \mathrm{~h}^{-1}$ & Tarboton et al. [1995] \\
\hline Visual new snow albedo $\left(\alpha_{v o}\right)$ & 0.85 & Tarboton et al. [1995] \\
\hline Near-infrared new snow albedo $\left(\alpha_{i r o}\right)$ & 0.65 & Tarboton et al. [1995] \\
\hline Bare ground albedo $\left(\alpha_{b g}\right)$ & 0.25 & Tarboton et al. [1995] \\
\hline Thermally active depth of soil $\left(d_{e}\right)$ & $0.1 \mathrm{~m}$ & Yои [2004] \\
\hline Thermal conductivity of snow $\left(\lambda_{s}\right)$ & $0.278 \mathrm{~W} \mathrm{~m}^{-1} \mathrm{~K}^{-1}$ & Mahat and Tarboton [2012] \\
\hline Thermal conductivity of soil $\left(\lambda_{g}\right)$ & $1.111 \mathrm{~W} \mathrm{~m}^{-1} \mathrm{~K}^{-1}$ & Mahat and Tarboton [2012] \\
\hline Atmospheric transmissivity for cloudy conditions $\left(a_{s}\right)$ & 0.25 & Shuttleworth [1993] \\
\hline Atmospheric transmissivity for clear conditions $\left(a_{s}+b_{s}\right)$ & 0.75 & Shuttleworth [1993] \\
\hline Ratio of direct to total radiation for clear sky $(\lambda)$ & $6 / 7$ & Mahat and Tarboton [2012] \\
\hline $\begin{array}{l}\text { Richardson number upper bound for stability } \\
\text { correction }\left(R_{i \max }\right)\end{array}$ & 0.16 & Koivusalo [2002] \\
\hline Emissivity of canopy (conifer/deciduous) $\left(\varepsilon_{c}\right)$ & 0.98 & Bonan [1991] \\
\hline Interception unloading rate $\left(U_{s}\right)$ & $0.00346 \mathrm{~h}^{-1}$ & Hedstrom and Pomeroy [1998] \\
\hline Leaf width $(w)$ & $0.04 \mathrm{~m}$ & Bonan [1991] \\
\hline
\end{tabular}

$$
\overline{G_{b}}=\int_{0}^{h} 0.01 \sqrt{u(z) / w} \mathrm{~d} z / h .
$$

[27] Substituting the height dependent value of $u(z)$ from equation (17) and integrating yields

$$
\overline{G_{b}}=\frac{0.02}{n} \sqrt{u(h) / w}[1-\exp (-n / 2)]
$$

[28] The mean canopy conductance per unit ground area is obtained by multiplying mean leaf conductance $\overline{G_{b}}$ with effective leaf area index $L F$, where $L$ is leaf area index and $F$ is canopy coverage fraction. Thus, mean canopy resistance is

$$
R_{l}=1 /\left(\overline{G_{b}} L F\right)
$$

\subsection{Snow Interception and Water Vapor Flux}

[29] Hedstrom and Pomeroy's [1998] event-based snowfall interception model was used to develop a continuous interception component for inclusion in UEB. This model is similar to the rainfall interception model developed by Aston [1979]. Hedstrom and Pomeroy [1998] also present an empirical relationship for estimating the snow mass unloading from interception that was used. The details of the snow interception and unloading processes are given by Mahat [2011].

[30] Sublimation terms $E_{S}$ and $E_{c}$ in equations (2) and (3), respectively, are determined from the corresponding latent heat fluxes using

$$
E_{c}=-\frac{Q_{e c}}{\rho_{w} h_{v}} \text { and } E_{s}=-\frac{Q_{e s}}{\rho_{w} h_{v}},
$$

where $\rho_{w}$ is the density of water $\left(\mathrm{kg} \mathrm{m}^{-3}\right)$. The negative sign reflects the convention that $Q_{e c}$ and $Q_{e s}$ are the energy additions to the canopy and surface, while $E_{s}$ and $E_{c}$ are the losses. Total sublimation is obtained by adding $E_{s}$ and $E_{c}$.

\subsection{Radiation}

[31] To estimate the net radiation below, in, and above the canopy, the penetration of radiation through the canopy was based on a two-stream approximation, accounting for multiple scattering. This approach assumes, as an approximation following Monteith and Unsworth [1990], that multiple scattering occurs along a single path, thereby avoiding the intractable complexity of scattering in multiple directions. It also considers multiple reflections between the canopy and surface, treating direct and diffuse radiations separately. A detailed description of how net radiation is calculated below, in, and above the canopy is given by Mahat and Tarboton [2012].

Table 2. Site Variables

\begin{tabular}{lccc}
\hline & \multicolumn{3}{c}{ Values } \\
\cline { 2 - 4 } & $\begin{array}{c}\text { Niwot } \\
\text { Ridge }\end{array}$ & $\begin{array}{c}\text { TWDEF } \\
\text { (Conifer) }\end{array}$ & $\begin{array}{c}\text { TWDEF } \\
\text { (Deciduous) }\end{array}$ \\
\hline Leaf area & 4.2 & 4.5 & 1.0 \\
$\quad$ index $L$ & & & \\
Canopy cover fraction $F$ & 0.83 & 0.7 & 0.7 \\
Canopy height $h(\mathrm{~m})$ & 11.4 & 15 & 15 \\
Wind decay coefficient $n$ & 0.9 & 1.5 & 0.6 \\
Tree profile shape parameter $y$ & 2 & 2 & 1 \\
Slope ${ }^{\circ}$ ) & 3.7 & 2.0 & 5.0 \\
Aspect ${ }^{\circ}$ clockwise from $\left.\mathrm{N}\right)$ & 90 & 300 & 0 \\
Latitude ${ }^{\circ}$ ) & 40.03 & 41.86 & 41.86 \\
Longitude $\left({ }^{\circ}\right)$ & 105.55 & 111.50 & 111.50 \\
Branch interception capacity, & 6.6 & 6.6 & 6.6 \\
$\quad$ BIC $\left(\mathrm{kg} \mathrm{m}^{-2}\right.$ ) & & & \\
Average atmospheric & 70,623 & 74,000 & 74,000 \\
$\quad$ pressure $(\mathrm{Pa})$ & & & \\
\hline
\end{tabular}




\section{EC Flux Measurements}

[32] EC is a direct way to measure the turbulent transfer of heat and mass over the surface [Kaimal and Finnigan, 1994]. EC techniques have been applied to estimate the turbulent energy fluxes and the subsequent vapor losses from the snow pack in open areas [e.g., Culle et al., 2007], from snow below the canopy [e.g., Marks et al., 2008], from intercepted snow in the canopy [e.g., Nakai et al., 1999; Suzuki and Nakai, 2008], and from both the canopy and below-canopy snow [e.g., Jarosz et al., 2008; Molotch et al., 2007]. The below-canopy turbulence and the subsequent vapor fluxes have been modeled and validated in comparison with the EC measurements [e.g., Marks et al., 2008]. Similarly, the above-canopy turbulence and the vapor fluxes have been modeled and validated in comparison with the EC measurements [e.g., Parviainen and Pomeroy, 2000]. There are several possible sources of error in the EC measurements, and the production of high-quality data requires applying corrections that include coordinate rotation, data filtering, removal of erroneous spikes, and lag time determination [Reba et al., 2009]. With these quality controls Reba et al. [2009] suggested that EC-measured data could be used for fundamental research, such as the snow mass and energy balances studies to improve the physically based snow models.

[33] The EC method is used to calculate the turbulent fluxes of the sensible heat $Q_{h}$ and latent heat $Q_{e}$ based on the covariance between the respective scalars (temperature and water vapor density) and vertical wind measured at a high frequency.

$$
\begin{gathered}
Q_{h}=\rho_{a} c_{p} \overline{T^{\prime} w^{\prime}} \\
Q_{e}=h_{v} \overline{\rho_{v}^{\prime} w^{\prime}}
\end{gathered}
$$

where $T^{\prime}, w^{\prime}$, and $\rho_{v}^{\prime}$ are the deviations from the time average of temperature, vertical wind speed, and water vapor density, respectively.

[34] EC data quality control and processing include despiking, data gap filling, coordinate rotation, block averaging, sonic temperature correction, air density correction, and analysis of IRGA errors, high-frequency losses, and instrument surface heat exchange [Foken and Wichura, 1996; Reba et al., 2009]. Spikes within the data caused by the instrumental malfunction (electronic spikes) or by any perturbation of the measurements (e.g., precipitation) were removed. Data sets were tested for stationarity using the method described by Richardson et al. [2012].

[35] An averaging time of $30 \mathrm{~min}$ of $10 \mathrm{~Hz}$ measurements was used. The mean lateral and vertical wind velocities were set to zero using a mathematical coordinate rotation; only the lateral component was corrected for in processing the below-canopy data [Baldocchi and Hutchison, 1987]. The sonic anemometers' virtual air temperatures were corrected, accounting for wind speed normal to the sonic path and humidity effects [Schotanus et al., 1983]. Time delay between the vertical velocity and the scalar sensor signals were checked empirically by maximizing the cross correlation between the sensors and the respective scalars. This time lag is due to the transit time in the inlet tubing or instrument separation. Scalar signals were shifted in time by the time lag relative to the vertical wind velocity, and covariance was calculated maximizing the cross correlation between the vertical wind and respective scalar signals.

[36] Air was drawn from an inlet located close to the sonic anemometer path and passed through a heat exchanger to reduce temperature fluctuations. Air flow then passed through the IRGA before analysis. Bringing the air to a constant temperature in the analyzer eliminates the need for corrections due to the sensible heat flux since this eliminates the temperature-induced density fluctuations [Webb et al., 1980]. Flow rate through the analyzer was maintained constant by a carbon-vane pump to reduce the pressure fluctuations. Increase in pressure may lead to the condensation of the water vapor if the local water vapor pressure exceeds the dew point [Leuning and Judd, 1996]. This flow was maintained to be turbulent flow, so the attenuation of concentration of fluctuations within the tube would not cause underestimation of the fluxes. See Molotch et al. [2007] and Turnipseed et al. [2002, 2003] for complete details of EC data quality control and corrections.

[37] Energy balance closure was evaluated to derive linear regression coefficients (slope and intercept) using a linear regression between the half hourly estimates of the turbulent flux $\left(Q_{h}+Q_{e}\right)$ and the difference between the radiation and ground heat flux $\left(Q_{n e t}-Q_{g}\right)$. The relationship between the above-canopy combined turbulent fluxes $\left(Q_{h}+Q_{e}\right)$ and $\left(Q_{n e t}-Q_{g}\right)$ in $\mathrm{W} \mathrm{m} \mathrm{m}^{-2}$ was $y=0.77 x+13$ $\left(R^{2}=0.89 ; p<0.01\right)$ [Molotch et al., 2007]. This indicates reasonable energy balance closure, but that there may be some error attributable to measured EC fluxes.

[38] Snowpack sublimation from below the canopy was determined from the below-canopy EC measurements, and total sublimation from the system was determined from the above-canopy EC measurements. Water vapor fluxes associated with sublimation of intercepted snow were determined as the difference between the measured above- and below-canopy fluxes.

\section{Model Application}

[39] The below-canopy EC data were only available at Niwot Ridge for a limited period from 1 March to 30 April for the year 2002. However, for eight other years, records of the above-canopy EC data were available at Niwot Ridge. Given this data availability, the model was first tested, and the adjustable parameters calibrated, against the above- and below-canopy EC measurements for this 2002 period. We refer to this as the test period. The model was then further evaluated using 2 months of the above-canopy EC-measured flux data from eight additional years (20032010). For model evaluation at Niwot Ridge the period from 1 January to the end of February each year was selected, as there is appreciable precipitation and intercepted snow in the canopy, while transpiration from the canopy is minimal or zero during this period. We refer to these 8 years of January/February Niwot Ridge data as the evaluation periods. UEB is a snow model and does not attempt to model transpiration. The selection of these periods for comparison avoids periods where the canopy is snow free and unmodeled transpiration may be part of the measurements and confound interpretations. 

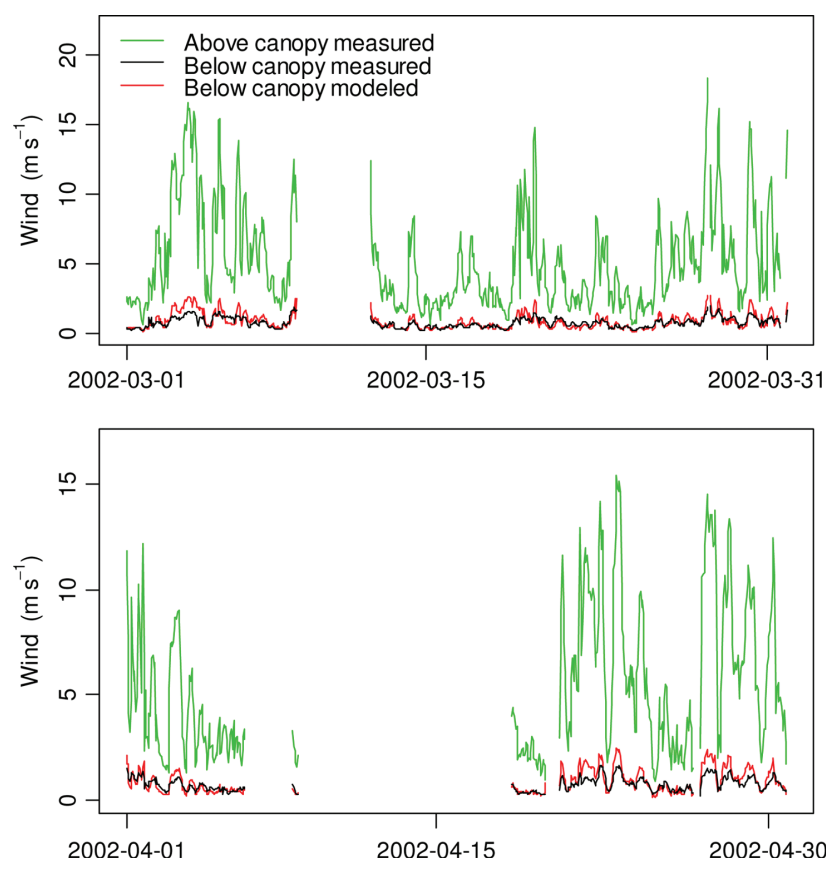

Figure 2. Time series of hourly measured above-canopy wind and measured and modeled below-canopy winds for the months of March and April in 2002 for the Niwot Ridge AmeriFlux site.

[40] TWDEF has complete records of the above open and beneath deciduous and forest canopy wind speeds for 2008-2010. For consistency with the Niwot Ridge test period, and to focus on a period when modeling fluxes is important, the measured and modeled wind speeds during March and April were compared for these years.

[41] The model was initialized with the below-canopy snow water equivalent and energy content state variables estimated based on the measured snow depth and air temperature, and run using the above-canopy meteorological measurements of precipitation, air temperature, humidity, and wind as inputs. The canopy snow water equivalent state variable was initialized at zero. The vegetation parameters used in the model are leaf area index, canopy height, and canopy cover. Roughness length for the canopy was estimated using equation (19). Snow surface roughness length $z_{o s}$ below the canopy and exponential decay coefficient $n$ were adjusted to have the model results match the measurements during the calibration period in 2002. The same $z_{\text {os }}$ value was extended to TWDEF (conifer and deciduous) while $n$, which is based on the forest properties, was estimated separately for the TWDEF coniferous and deciduous sites based on the TWDEF wind speed data for 2008-2010. Other snowmelt model parameters used in this work follow the prior work [Mahat and Tarboton, 2012; Tarboton and Luce, 1996; You, 2004] (Table 1) with the site variables specific to this setting given in Table 2 .

[42] The model predicts the snow surface temperature, the snow average temperature, the snow interception, the below-canopy wind speed, the above- and below-canopy turbulent energy fluxes, the radiation, and the snow water equivalent. The above-canopy wind speed is the critical input to the wind and flux components of the model, together with other inputs of air temperature, humidity, solar radiation, and precipitation that drive other aspects of the model. At Niwot Ridge the above-canopy measurements of the wind speed were used to drive the model. At TWDEF the above-canopy measurements of wind were not available, so wind speed measured in a nearby open meadow was assumed to be equivalent to the above-canopy wind at a height $z_{m}=h+2 \mathrm{~m}$.

[43] The mean of the difference (bias), root-mean-square error (RMSE), and correlation between the measured and modeled wind and flux variables were used as criteria for the evaluation of the model's flux components. We did not use the coefficient of determination $\left(R^{2}\right)$ as a metric because, when not used in a regression context, and in the presence of bias, it can result in off-putting negative values that detract from the interpretation of the cause of the bias differences.

\subsection{Simulation Results}

\subsubsection{Wind}

[44] The below-canopy wind component was tested against one set of the below-canopy wind measurements from Niwot Ridge and two sets of the below-canopy wind (conifer and deciduous) from TWDEF. Simulated values of the below-canopy winds compared favorably with the observations made below the forest canopy at Niwot Ridge (Figures 2 and 3) and below the deciduous and conifer forest canopies at TWDEF. The below-canopy wind speed comparisons for TWDEF are included in the supporting information. A higher correlation between the modeled and observed values was found for Niwot Ridge in comparison to TWDEF, although there was more bias in the Niwot Ridge comparisons (Table 3).

[45] In comparison with the deciduous forest wind, modeled conifer forest wind was better correlated with the observations at TWDEF. The mean observed wind value below the conifer canopy was about half of that observed below the deciduous canopy. The greater density of coniferous forest canopy results in lower below-canopy wind

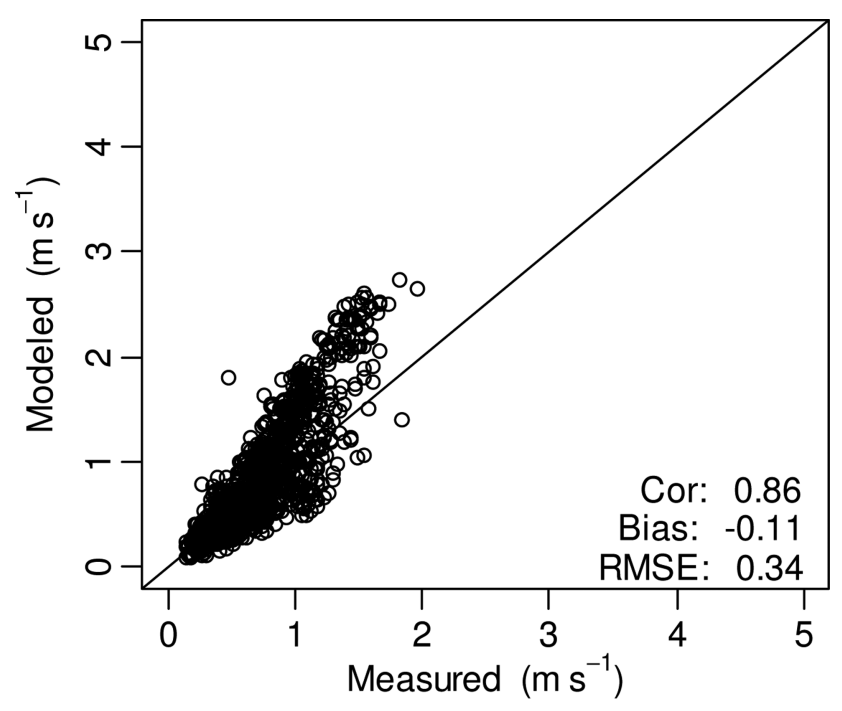

Figure 3. Scatterplot of hourly measured and modeled below-canopy winds for the months of March and April in 2002 for the Niwot Ridge AmeriFlux site. Cor, correlation; RMSE, root-mean-square error. 
Table 3. Comparative Statistics Between Modeled and Observed Below-Canopy Wind Speed

\begin{tabular}{lcccc}
\hline \multicolumn{1}{c}{ Site } & Year & Correlation & Bias & RMSE \\
\hline Niwot Ridge & 2002 & 0.86 & -0.11 & 0.34 \\
TWDEF conifer & 2008 & 0.71 & 0.05 & 0.3 \\
& 2009 & 0.6 & 0.05 & 0.33 \\
TWDEF deciduous & 2010 & 0.6 & 0.06 & 0.32 \\
& 2008 & 0.56 & -0.15 & 0.75 \\
& 2009 & 0.54 & 0.02 & 0.7 \\
& 2010 & 0.53 & 0 & 0.69 \\
\hline
\end{tabular}

speeds. Larger leaf area index and $n$ values in the model for coniferous canopy capture this effect.

\subsubsection{Energy Fluxes}

[46] Table 4 presents the correlation, the bias, and the RMSE for the differences between the modeled and observed above-canopy fluxes for both the test and evaluation periods at Niwot ridge. The model predictions of the above-canopy (total) sensible heat flux $Q_{h}$ followed the above-canopy (total) EC-measured sensible heat flux reasonably closely with a correlation of 0.85 (Figure 4) during the 2002 test period. While there is scatter in the modeled versus measured hourly values, the scatterplot biases observed are almost 0 . The cumulative plot and the mean diurnal variation plot (Figures $4 \mathrm{c}$ and $4 \mathrm{~d}$ ) also showed nice agreements between the modeled and EC-measured values. The mean diurnal variations were evaluated by averaging the measurements available for each hour of the day across all days. This shows the model's ability to, in an average sense, capture the diurnal cycle and complements the examination of time series (Figure $4 \mathrm{a}$ ) and pointwise scatterplots (Figure 4b). For the eight evaluation years, sensible heat correlation coefficients range from 0.75 to 0.85 , and biases range from -24.22 to $4.83 \mathrm{~W} \mathrm{~m}^{-2}$ (Table 4). Some of these values are larger, and some are smaller than the values obtained for the 2002 test period. However, all evaluation periods showed smaller RMSE values in comparison with the test period RMSE, possibly due to the evaluation period being the months of January and February, when fluxes are smaller, but the test period being March and April when below-canopy fluxes were available in 2002 . Additional comparisons of the modeled versus EC-measured above-canopy sensible heat fluxes for January and February in 2009 and 2010 are included in the supporting information. These years were chosen because they include low and high RMSE as well as low and high biases for both sensible and latent heat fluxes. The differences between the modeled and measured values in Figure 4 as well as figures in the supporting information provide quantification of uncertainty in the ability to quantify sensible heat fluxes in these conditions, both using measurements and modeling.

[47] The month of April during the 2002 test period showed a significant carbon uptake implying transpiration. Thus, the above-canopy (total) latent heat flux $Q_{e}$ presented for the 2002 test period is for the month of March only (Figure 5). During both the test and evaluation periods the relative values of the bias and RMSE are about the same as for $Q_{h}$, with RMSE close to $15 \%$ of the range of the data. However, there was more scatter indicated by the lower correlations ranging from 0.37 to 0.54 for the latent heat flux (Table 4). While there is scatter in the modeled versus measured hourly values, the match of the cumulative plot of the latent heat flux (Figure 5c) indicates that hourly errors offset each other when aggregated over time. The mean diurnal cycles also appear to be reasonably quantified (Figure 5d). Additional comparisons of the modeled versus EC-measured above-canopy latent heat fluxes for January and February in 2009 and 2010 are included in the supporting information.

[48] The EC measurements below the canopy showed upward (away from the snow surface) sensible heat flux $Q_{h s}$ during the daytime and downward (toward the snow surface) sensible heat flux during the nighttime (Figure 6). The model captured the nighttime, downward sensible heat flux quite well but did not represent the measured daytime, upward sensible heat flux. The model is driven by temperature gradients, and an upward flux requires the air temperature to be lower than the snow surface temperature which is capped at freezing $\left(0^{\circ} \mathrm{C}\right)$.

[49] Time series of the hourly below-canopy latent heat flux showed a general agreement between the observed and modeled values with a correlation of 0.47 , a bias of $1.06 \mathrm{Wm}^{-2}$, and a RMSE of $21.8 \mathrm{Wm}^{-2}$ (Figure 7). Though the correlation value was not large, the overall cumulative latent heat flux from the snow surface for both the measured and modeled values was similar. Due to the poor correlation and shift in some modeled higher hourly values, an early peak in the modeled mean diurnal variations was observed compared with the EC-measured values (Figure 7d).

\subsubsection{Sublimation}

[50] Simulations of the cumulative above-canopy snow sublimation match the observed values well during both the test and evaluation periods. A total of $35 \mathrm{~mm}$ of precipitation was recorded during the March portion of the test period in 2002 (Figure 8). During that period the above- and below-canopy EC measurements showed about $29 \mathrm{~mm}$ and $10 \mathrm{~mm}$ of sublimation, respectively. The model simulations of total sublimation compared well with these observations showing about 27 and $10 \mathrm{~mm}$ of the above- and below-canopy sublimation, respectively. The EC-measured net canopy sublimation was calculated by subtracting the below-

Table 4. Correlation, Bias, and RMSE for Differences Between Modeled and EC-Measured Above (Total) Canopy Fluxes at Niwot Ridge During Test Periods from 1 March to 30 April 2002 for $Q_{h}$ and 1 to 31 March 2002 for $Q_{e}$ and Evaluation Periods from 1 January to the End of February in 2003-2010

\begin{tabular}{cccccccc}
\hline & \multicolumn{5}{c}{ Above (Total) Canopy } \\
\cline { 2 - 4 } & \multicolumn{3}{c}{$Q_{h}\left(\mathrm{~W} \mathrm{~m}^{-2}\right)$} & & \multicolumn{3}{c}{$Q_{e}\left(\mathrm{~W} \mathrm{~m} \mathrm{~m}^{-2}\right)$} \\
\cline { 2 - 5 } \cline { 6 - 8 } Year & Correlation & Bias & RMSE & & Correlation & Bias & RMSE \\
\hline 2002 & 0.85 & -7.56 & 102.9 & & 0.54 & 3.35 & 45 \\
2003 & 0.75 & -4.59 & 108.1 & & 0.53 & -1.12 & 36 \\
2004 & 0.82 & -19.85 & 106.3 & & 0.49 & 1.3 & 37.7 \\
2005 & 0.84 & -7.84 & 94.2 & & 0.51 & -5.21 & 34.6 \\
2006 & 0.84 & 4.83 & 97.9 & & 0.53 & -5.77 & 41.8 \\
2007 & 0.76 & -5.77 & 118 & & 0.54 & -0.05 & 48.1 \\
2008 & 0.82 & -19.54 & 110.6 & & 0.42 & 1.96 & 45.6 \\
2009 & 0.84 & -4.5 & 92.3 & & 0.37 & -0.39 & 42.4 \\
2010 & 0.84 & -24.22 & 105.2 & & 0.49 & 3.37 & 33.8 \\
\hline
\end{tabular}



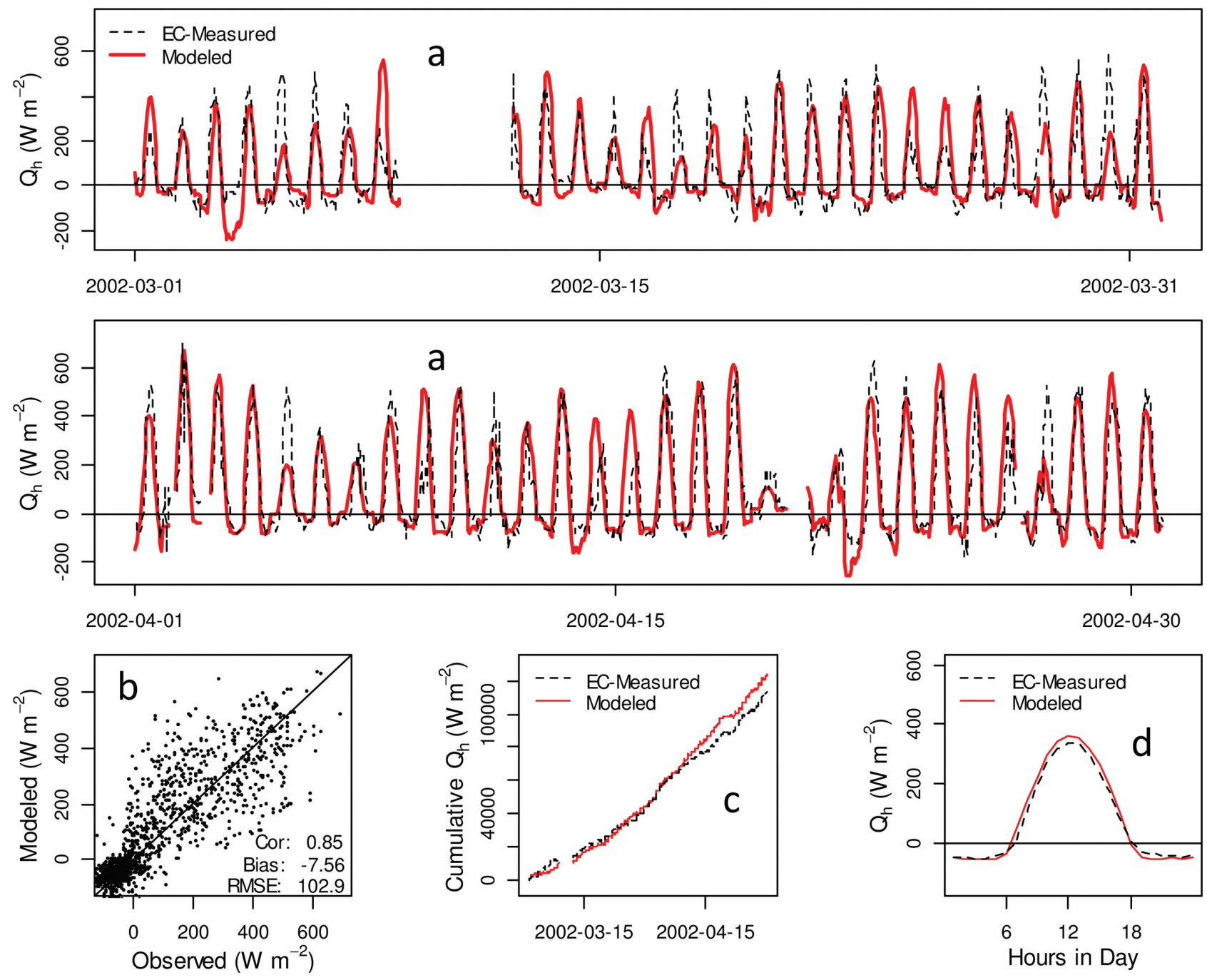

Figure 4. Total above-canopy EC-measured and modeled sensible heat flux $\left(Q_{h}\right)$, aggregated hourly and plotted with upward fluxes positive for the period 1 March to 30 April 2002: (a) time series, (b) scatterplot, (c) cumulative plot, and (d) mean diurnal variations. Cor, correlation; RMSE, root-mean-square error.

canopy EC measurement from the above-canopy EC measurement and compared with the modeled canopy sublimation. The modeled cumulative net canopy sublimation values tracked well with the EC measurements.

[51] During the eight evaluation periods the above-canopy EC-measured sublimation values ranged from 40 to 74 $\mathrm{mm}$ with a mean of $47 \mathrm{~mm}$. The model simulated the above-canopy sublimation values during these periods ranged from 46 to $78 \mathrm{~mm}$ with a mean of $60 \mathrm{~mm}$. The mean below-canopy sublimation simulated by the model for the months of January and February for the 8 years combined was $28 \mathrm{~mm}$.

\subsubsection{Parameter Sensitivity}

[52] Developing the model involved a lot of choices related to how to parameterize quantities such as $z_{o s}, z_{o c}, d$, and leaf width $w$ involved in the calculation of resistances $R_{a}, R_{c}$, and $R_{l}$. Selections were based on the literature and some judgment, and the validity of the selections is sup- ported by the overall performance of the model in comparison to overall snow water equivalent, radiation measurements [Mahat and Tarboton, 2012] and flux measurements in this study. While the model is physically based, there is uncertainty in the values for many of the physical parameters, and the performance of the model is enhanced by the adjustment of some of them. Model sensitivity was evaluated using plausible ranges for the parameters critical to the quantification of fluxes to give a sense of how important it is to constrain uncertainty in these parameters (Table 5). This analysis was done using the cumulative sensible and latent heat fluxes over the period 1 March to 30 April 2002 and 1-31 March 2002, respectively, for which results are given in Figures 4 and 5. The base parameters in the model were individually adjusted to the lower and upper bound of a range given for each parameter. Sensitivity was reported (Table 5) in terms of the percentage change in total flux over the period given the parameter change, i.e., evaluated as Changed-Base/Base $\times 100$. 


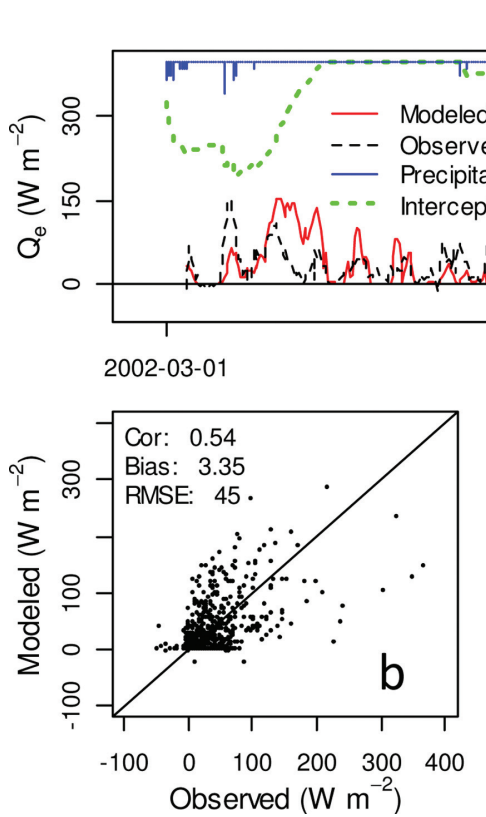

Figure 5. (a) Time series of total above-canopy EC-measured and modeled latent heat flux $\left(Q_{e}\right)$, aggregated hourly and plotted with upward fluxes positive. Precipitation and interception plotted downward following the right axis. (b) Scatterplot of EC-measured and modeled latent heat flux $\left(Q_{e}\right)$, (c) cumulative plot, and (d) mean diurnal variations for the period 1-31 March 2002. Cor, correlation; RMSE, root-mean-square error.

[53] In examining the sensitivity of the model to parameters critical for the quantification of turbulent fluxes (Table 5), the most sensitive parameters are $L \times F, n, z_{m s}$, and $z_{o s}$. Leaf area index $L$ and forest canopy fraction $F$ were evaluated as a product because that is how they are used in the model. $L$ and $F$ are the physical properties of the forest canopy, and this sensitivity speaks to the importance of quantifying them in using the model to predict snow accumulation and melt, and sublimation from snow in settings with heterogeneous vegetation. The results were also relatively sensitive to $n$, the parameter that represents the decrease in wind speed through the canopy, and $z_{m s}$ and $z_{\text {os }}$ parameters that relate to the above surface logarithmic boundary layer profile and at which elevation it switches to exponential. Canopy height $h$ is also a physical property of the canopy, but the sensitivity to $h$ is less than $L \times F$. Sensitivity was relatively small to the other parameters evaluated.

\section{Discussion}

[54] This study has developed a flux component for an energy balance snowmelt model and compared the model simulated above- and below-canopy turbulent fluxes of sensible and latent heat with the EC-measured fluxes to evaluate the model performance. The model was generally able to represent the above-canopy sensible heat flux, latent heat flux, and also snow mass loss through sublimation. In some years there was bias, more so in sensible heat flux than latent heat flux and more often than not with modeled upward sensible heat being greater in magnitude than observed. These discrepancies may be due to the model errors or the measurement errors associated with EC energy balance closure. They reflect the present degree of uncertainty in quantifying flux with this model and the information available. The model's predictions of the belowcanopy wind, the latent heat flux, and the subsequent snow mass loss were also generally good, but the model did not do as well in predicting the below-canopy sensible heat flux during the daytime. The nighttime sensible heat flux was reasonably captured by the model. Most of the time the modeled temperature gradient was downward $\left(T_{a c}>T_{s}\right)$ and that downward gradient resulted in downward sensible heat flux. The EC measurements showed downward sensible heat flux $\left(T_{a c}>T_{s}\right)$ during the nighttime and upward sensible heat flux $\left(T_{s}>T_{a c}\right)$ during the daytime. Modeling a daytime upward sensible heat flux requires the surface temperature greater than the air temperature. The model adheres to the physical principal that the temperature of the snow surface cannot be greater than freezing and so is unable to represent these upward measurements of sensible heat flux by EC when $T_{a c}>0$. There is some suggestion that this discrepancy may be due to complex mountain slope circulation events, and there are times when above-canopy winds are downslope, but the below-canopy winds are much closer to zero in speed and recorded to be upslope. This would change the effective footprint of the EC measurements.

[55] Although EC is treated as a measurement technique, there are many assumptions in its calculation that can be sensitive to a complex suite of site conditions [Marks et al., 2008]. The below-canopy EC flux measurements may be questionable because the underlying assumptions for this method may not be valid in the conditions prevailing there, namely, low wind speed, strong heterogeneity, and intermittent turbulence [Baldocchi et al., 2000; Blanken et al., 

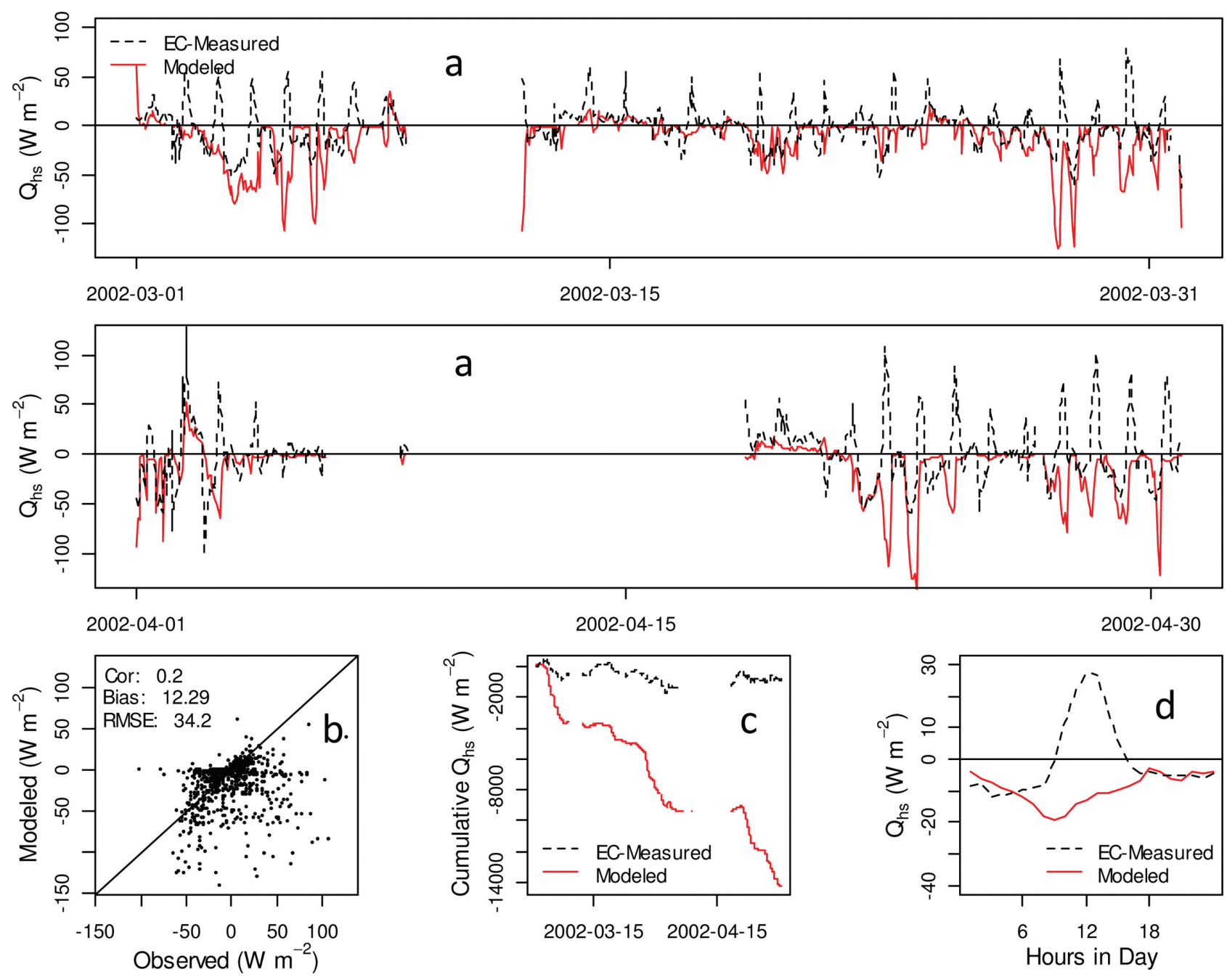

Figure 6. Below-canopy EC-measured and modeled sensible heat flux $\left(Q_{h s}\right)$, for the period 1 March to 30 April 2002 aggregated hourly and plotted with upward fluxes positive: (a) time series, (b) scatterplot, (c) cumulative plot, and (d) mean diurnal variations. Cor, correlation; RMSE, root-mean-square error.

1998; Constantin et al., 1999]. During the periods with low wind speed, very stable conditions with large surface temperature and moisture gradients may occur, which are challenging to both model and measure using EC [Marks et al., 2008]. Furthermore, heterogeneity of the subcanopy environment due to forest structure, fallen litter, and tree branches may lead to advection and questions related to the EC footprint and may lead to violation of some of the assumptions used in EC flux calculations associated with continuity of the upwind fetch [Foken and Wichura, 1996; Leuning and Judd, 1996].

[56] There may be modeling problems too. Uncertainties exist in the assumptions of surface roughness length, resistances, and the derivation of below-canopy wind in the model. Assumed equal resistances for the transfer of heat and water vapor used in the turbulence modeling may not be strictly valid below the canopy. Helgason and Pomeroy [2011] found that in complex mountain terrain due to intermittency of wind gusts, the boundary layer may not be in equilibrium and turbulence may not be related to the local gradient making the application of gradient techniques problematic. Helgason and Pomeroy [2012] also found the modeled sensible heat flux toward the snow surface higher than the EC-measured sensible heat flux. Representing the complexity of mountain slope circulation and intermittency is beyond the scope of this model. While there may be discrepancies when using temperatures and fluxes measured at specific points, the physical basis of the approach and the success of the model for more aggregate or cumulative quantities suggest that the approach that relies on gradients is physically reasonable and practical for a model that needs to be simple enough to apply over large areas.

[57] The below-canopy wind speed was calculated as an exponential function of canopy height following Koivusalo [2002], Bonan [1991], and Dolman [1993]. The exponential decay coefficient $n$ that is required to calculate the belowcanopy wind speed has been reported to have a value between 2 and 4 [Bonan, 1991; Brutsaert, 1982]. In testing the model with the below-canopy wind measurements at Niwot Ridge and TWDEF sites, the $n$ values that resulted in the below-canopy wind speed best matching the measurements ranged from 0.6 to 1.5 for leaf area index ranging 

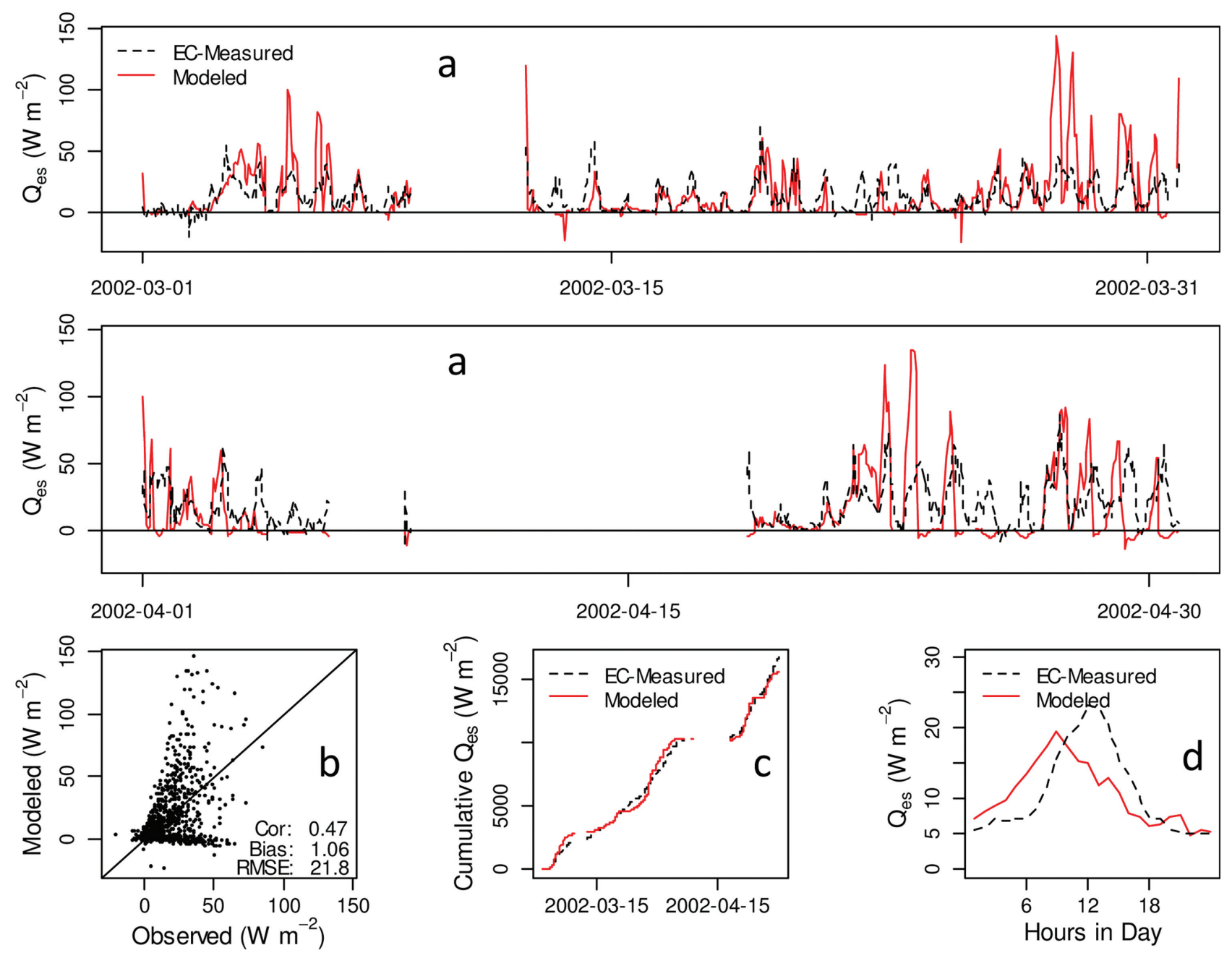

Figure 7. Below-canopy EC-measured and modeled latent heat flux $\left(Q_{e s}\right)$, for the period 1 March to 30 April 2002 aggregated hourly and plotted with upward fluxes positive: (a) time series, (b) scatterplot, (c) cumulative plot, and (d) mean diurnal variations. Cor, correlation; RMSE, root-mean-square error.

from 1 to 4.5 , with the increasing $n$ values for the increasing leaf area index. This pattern, though determined based on the limited data in this work, appears consistent with the below-canopy wind speed being sensitive to forest type (conifer, deciduous, and mixed) and density.

[58] The snow surface roughness length below the canopy was adjusted to match the measurements of below-canopy latent heat flux and vapor loss. This adjustment to $z_{o s}=0.1 \mathrm{~m}$ from the previous open area value of $0.01 \mathrm{~m}$ may represent the increased turbulence in wind below a canopy but may also express the limitations of assuming logarithmic wind and diffusivity profiles near the surface below a canopy. The above-canopy solutions were found to be less sensitive to this snow surface roughness length and changed insignificantly with this adjustment.

[59] The modeled rate of the net canopy snow sublimation loss during the test period in 2002 (1 March to 30 April) and the modeled rate of net canopy sublimation loss during the evaluation periods from 2003 to 2010 (1 January to the end of February) were found to be equivalent about $0.55 \mathrm{~mm} \mathrm{~d}^{-1}$. This value is similar to the net canopy

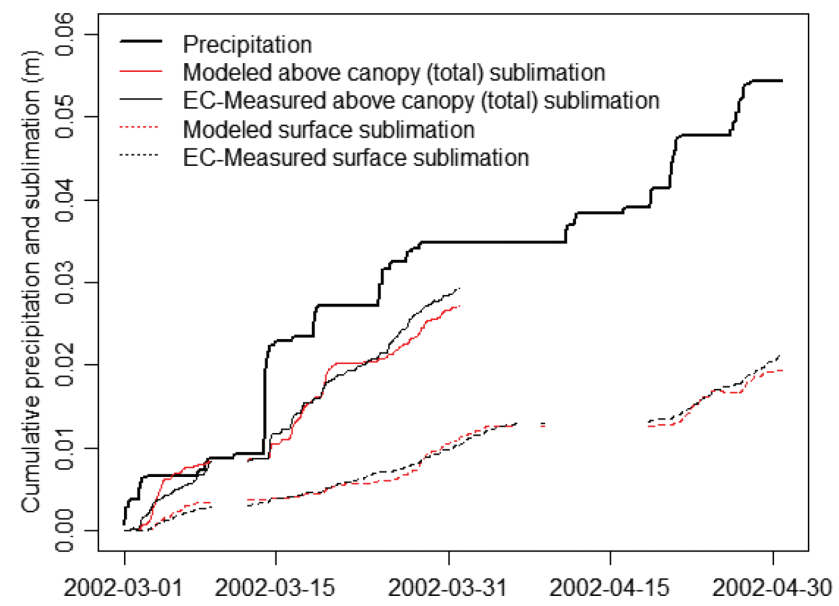

Figure 8. Cumulative precipitation and measured and modeled sublimation from above the canopy, below the canopy, and the total for the period 1 March to 30 April 2002. 
Table 5. Sensitivity of Cumulative Fluxes for the Period 1 March to 30 April 2002 for $Q_{h}$ and $Q_{h s}$, and 1 to 31 March 2002 for $Q_{e}$ and $Q_{e s}$

\begin{tabular}{|c|c|c|c|c|c|c|c|}
\hline \multirow[b]{3}{*}{ Parameters/Variables } & \multirow[b]{3}{*}{$\begin{array}{l}\text { Base Parameters } \\
\text { Used in the Model }\end{array}$} & & & \multicolumn{4}{|c|}{$\begin{array}{l}\text { Percentage Change Evaluated as } \\
\text { Changed-Base/Base } \times 100\end{array}$} \\
\hline & & & & & al Flux & & $\begin{array}{l}\text { Sur- } \\
\text { uxes }\end{array}$ \\
\hline & & \multicolumn{2}{|c|}{$\begin{array}{l}\text { Parameters Used in the } \\
\text { Sensitivity Analysis }\end{array}$} & $Q_{h}$ & $Q_{e}$ & $Q_{h s}$ & $Q_{e s}$ \\
\hline Reference height above surface $z_{m s}(\mathrm{~m})$ & 2 & $z_{m s}$, lower & 1 & -19 & 65 & 136 & 136 \\
\hline \multirow{2}{*}{ Snow surface roughness length $z_{o s}(\mathrm{~m})$} & 0.1 & $z_{\text {os }}$, lower & 0.01 & 9 & -26 & -69 & -55 \\
\hline & & $z_{o s}$, upper & 0.3 & -12 & 37 & 86 & 83 \\
\hline \multirow[t]{2}{*}{ Thermal conductivity of snow, $\lambda_{s}\left(\mathrm{~W} \mathrm{~m}{ }^{-1} \mathrm{~K}^{-1}\right)$} & 0.278 & $\lambda_{s}$, lower & 0.05 & 0 & 0 & 0 & 3 \\
\hline & & $\lambda_{s}$, upper & 1 & 2 & 2 & -15 & 7 \\
\hline \multirow[t]{2}{*}{ Leaf area index times canopy cover fraction $L \times F$} & 3.486 & $L \times F$, lower & 0.7 & -92 & 94 & 308 & 322 \\
\hline & & $L \times F$, upper & 5 & 13 & -29 & -59 & -58 \\
\hline \multirow[t]{2}{*}{ Canopy height $h(\mathrm{~m})$} & 11.4 & $h$, lower & 4 & -5 & -28 & 7 & -43 \\
\hline & & $h$, upper & 20 & -1 & 14 & 7 & 26 \\
\hline Wind decay $n$ & & $n$, upper & 2 & 11 & -37 & -91 & -71 \\
\hline \multirow[t]{2}{*}{ Branch interception capacity $\left(\mathrm{kg} \mathrm{m}^{-2}\right)$} & 6.6 & Lower & 3 & 0 & 1 & -4 & 4 \\
\hline & & Upper & 10 & 1 & -2 & -4 & 3 \\
\hline \multirow[t]{2}{*}{ Forest profile indicator $y$} & 2 & $y$, lower & 1 & -2 & 9 & 10 & 20 \\
\hline & & $y$, upper & 3 & 2 & -9 & -20 & -16 \\
\hline \multirow[t]{2}{*}{ Leaf width $w(\mathrm{~m})$} & 0.04 & $w$, lower & 0.01 & 4 & -12 & -14 & -36 \\
\hline & & w, upper & 0.1 & -2 & 6 & -1 & 25 \\
\hline
\end{tabular}

sublimation rate $\left(0.5 \mathrm{~mm} \mathrm{~d}^{-1}\right.$, based on 2 months, February and March 1995 observation) reported by Parviainen and Pomeroy [2000] for Canadian boreal forest and slightly less than the net canopy sublimation rate $\left(0.65 \mathrm{~mm} \mathrm{~d}^{-1}\right.$, about $100 \mathrm{~mm}$ in 5 months from December to April in 1997-1998 and 1998-1999) reported by Storck et al. [2002] for Pacific Northwest forest in Oregon. The modeled below-canopy snow sublimation loss rates during the periods examined ranged from 0.27 to $0.59 \mathrm{~mm} \mathrm{~d}^{-1}$. These values are slightly higher than the below-canopy sublimation rate $\left(0.25 \mathrm{~mm} \mathrm{~d}^{-1}\right.$, about $22 \mathrm{~mm}$ in 86 days from 19 February to 15 May 2003) reported by Marks et al. [2008] for the Fraser Experimental Forest, Colorado. Sublimation rates are expected to vary based on the location and climatic conditions, but these comparisons serve to show that the model simulations are generally consistent with what others have found.

[60] Sensitivity analysis showed that the model results are sensitive to physical properties of the forest canopy ( $L$, $F$ ) and the parameter $n$, which also depends on the forest canopy properties. This highlights the importance of advancing remote sensing methods [e.g., Fassnacht et al., 1997; Running et al., 1989; Zheng and Moskal, 2009] for mapping and retrieving these parameters. The sensitivity to $n, z_{m s}$, and $z_{o s}$ that relate to the within-canopy wind profile emphasizes the need for research to better quantify the canopy wind profiles related to the canopy structure and the role these play in the turbulent fluxes. Other parameters that are less sensitive to the model results are probably reasonable to use as constants in the applications of the model at different locations.

\section{Summary and Conclusions}

[61] This paper has presented details of the turbulent flux components of a single-layer forest canopy model developed for use with the UEB snowmelt model. This approach fills the need for a model rigorous enough to capture the physics of the turbulent energy flux transfer through the forested canopies based on the practically available information. It uses the physically realistic representations of the processes involved while keeping the number of model parameters small, so as to be easy to apply in a spatially distributed fashion. The result is an enhanced model that represents snow energy and mass balances within and below the canopy, driven by the inputs of radiation and weather from above the canopy. The new canopy layer includes the representations for radiation, turbulent fluxes, and interception. The model is physically based with the goal of most parameters being transferable to different locations without calibration. The model was initially developed and applied at the TWDEF site. In this study the model was transferred, and flux components were tested, using EC data from Niwot Ridge. Both above and below the canopy turbulent fluxes were examined. The initial Niwot Ridge application of the model was to a period with both the below- and above-canopy measurements, and these were used to estimate the poorly constrained parameters. Then the model was further validated for different years with only the above-canopy data. The model was able to simulate fluxes generally in agreement with EC measurements. The results show that this parsimonious single-layer approach can provide results consistent with the observations based on the practically available information. The methods used here are not limited to UEB and could be used to calculate these fluxes in other snow models. Some unresolved discrepancies with the belowcanopy sensible heat fluxes were noted where measurements counter to the temperature gradient were not modeled. Fluxes in a direction opposite to a temperature gradient are inconsistent with essentially all theory, raising questions about the data that give rise to these 
discrepancies. Further work is needed to better quantify some of the model parameterizations and their relationship to vegetation properties. Specifically, the dependence of the wind exponential decay parameter on the leaf area index or the other canopy properties, and the surface roughness below the canopy need further evaluation.

[62] Acknowledgments. This research was supported by the USDACREES Utah drought management project award 2008-34552-19042. We also acknowledge the Niwot Ridge Long Term Ecological Research Program and support from the NSF EAR 1032308 and the NSF EAR 1032295 .

\section{References}

Anderson, E. A. (1976), A point energy and mass balance model of a snow cover, NOAA Tech. Rep. NWS 19, U.S. Dep. of Commer., Silver Spring, Md.

Andreadis, K. M., P. Storck, and D. P. Lettenmaier (2009), Modeling snow accumulation and ablation processes in forested environments, Water Resour. Res., 45, W05429, doi:10.1029/2008WR007042.

Aston, A. R. (1979), Rainfall interception by eight small trees, J. Hydrol., 42, 383-396.

Baldocchi, D. D., and B. A. Hutchison (1987), Turbulence in an almond orchard: Vertical variations in turbulent statistics, Boundary Layer Meteorol., 40(1), 127-146, doi:10.1007/bf00140072.

Baldocchi, D. D., B. E. Law, and P. M. Anthoni (2000), On measuring and modeling energy fluxes above the floor of a homogeneous and heterogeneous conifer forest, Agric. For. Meteorol., 102(2-3), 187-206, doi:10.1016/s0168-1923(00)00098-8.

Bartlett, P. A., M. D. MacKay, and D. L. Verseghy (2006), Modified snow algorithms in the Canadian land surface scheme: Model runs and sensitivity analysis at three boreal forest stands, Atmos. Ocean, 44(3), 207-222.

Blanken, P. D., T. A. Black, H. H. Neumann, P. C. Yang, Z. Nesic, R. Staebler, W. Chen, M. D. Novak, and G. D. Hortog (1998), Turbulent flux measurements above and below the overstory of a boreal aspen forest, Boundary Layer Meteorol., 89, 109-140.

Bonan, G. B. (1991), A biophysical surface energy budget analysis of soil temperature in the boreal forests of interior Alaska, Water Resour. Res., 27(5), 767-781

Brutsaert, W. (1982), Evaporation into the Atmosphere, 299 pp., Kluwer Acad., Dordrecht, Netherlands.

Caine, N. (1995), Temporal trends in the quality of streamwater in an alpine environment: Green lakes valley, Colorado Front Range, U.S.A., Geogr. Ann. A, 77(4), 207-220.

Cherkauer, K. A., L. C. Bowling, and D. P. Lettenmaier (2003), Variable infiltration capacity cold land process model updates, Global Planet. Change, 38(1-2), 151-159, doi:10.1016/s0921-8181(03)00025-0.

Choudhury, B. J., and J. L. Monteith (1988), A four-layer model for the heat budgets of homogeneous land surfaces, Q. J. Roy. Meteorol. Soc., $114,373-398$.

Cionco, R. M. (1972), A wind profile for canopy flow, Boundary Layer Meteorol., 3, 255-263.

Constantin, J., A. Grelle, A. Ibrom, and K. Morgenstern (1999), Flux partitioning between understorey and overstorey in a boreal spruce/pine forest determined by the eddy covariance method, Agric. For. Meteorol., 98 99, 629-643, doi:10.1016/s0168-1923(99)00129-x.

Culle, N. J., T. Molg, G. Kaser, K. Steffen, and D. R. Hardy (2007), Energy-balance model validation on the top of Kilimanjaro, Tanzania, using eddy covariance data, Ann. Glaciol, 46(1), 227-233.

Demarty, J., C. Ottle, C. Francois, I. Braud, and J. P. Frangi (2002), Effect of aerodynamic resistance modelling on SiSPAT-RS simulated surface fluxes, Agronomie, 22(6), 641-650, doi:10.1051/agro:2002052.

Dickinson, R. E., A. Henderson-Sellers, P. J. Kennedy, and M. F. Wilson (1986), Biosphere-atmosphere transfer scheme (BATS) for the NCAR community climate model, NCAR/TN-275+STR, Natl. Cent. for Atmos. Res., Boulder, Colo.

Dolman, A. J. (1993), A multiple-source land surface energy balance model use in general circulation models, Agric. For. Meteorol., 65(1-2), 21-45.

Ellis, C. R., and J. W. Pomeroy (2007), Estimating sub-canopy shortwave irradiance to melting snow on forested slopes, Hydrol. Processes, 21(19), 2581-2593, doi:10.1002/hyp.6794
Ellis, C. R., J. W. Pomeroy, T. Brown, and J. MacDonald (2010), Simulation of snow accumulation and melt in needleleaf forest environments, hydrol. earth syst. sci., 14(6) [Available at http://www.hydrol-earth-systsci.net/14/925/2010/.]

Essery, R., J. Pomeroy, J. Parviainen, and P. Storck (2003), Sublimation of snow from coniferous forests in a climate model, J. Clim., 16, 18551864.

Fassnacht, K. S., S. T. Gower, M. D. MacKenzie, E. V. Nordheim, and T. M. Lillesand (1997), Estimating the leaf area index of North Central Wisconsin forests using the Landsat Thematic Mapper, Remote Sens. Environ., 61(2), 229-245, doi:10.1016/s0034-4257(97)00005-9.

Foken, T., and B. Wichura (1996), Tools for quality assessment of surfacebased flux measurements, Agric. For. Meteorol., 78(1-2), 83-105, doi:10.1016/0168-1923(95)02248-1

Gelfan, A. N., J. W. Pomeroy, and L. S. Kuchment (2004), Modeling forest cover influences on snow accumulation, sublimation, and melt, J. Hydrometeorol., 5(5), 785-803.

Gerald, C. F. (1978), Applied Numerical Analysis, 2nd ed., 518 pp., Addison-Wesley, Reading, Mass.

Hedstrom, N. R., and J. W. Pomeroy (1998), Measurements and modelling of snow interception in the boreal forest, Hydrol. Processes, 12(10-11), 1611-1625.

Helgason, W., and J. W. Pomeroy (2011), Characteristics of the near-surface boundary layer within a mountain valley during winter, J. Appl. Meteorol. Climatol., 51(3), 583-597, 10.1175/jamc-d-11-058.1.

Helgason, W., and J. W. Pomeroy (2012), Problems closing the energy balance over a homogeneous snow cover during midwinter, J. Hydrometeorol., 13(2), 557-572, 10.1175/jhm-d-11-0135.1.

Hellstrom, R. A. (2000), Modeling meteorological forcing of snowcover in forests, Ph.D. dissertation, The Ohio State Univ., Columbus, Ohio.

Inclan, M. G., and R. Forkel (1995), Comparison of energy fluxes calculated with the Penman-Monteith equation and the vegetation models $\mathrm{SiB}$ and Cupid, J. Hydrol., 166(1995), 193-211.

Jarosz, N., Y. Brunet, E. Lamaud, M. Irvine, J.-M. Bonnefond, and D. Loustau (2008), Carbon dioxide and energy flux partitioning between the understorey and the overstorey of a maritime pine forest during a year with reduced soil water availability, Agric. For. Meteorol., 148(10), 1508-1523, doi:10.1016/j.agrformet.2008.05.001.

Jones, H. G. (1992), Plants and Microclimates, 2nd ed., 428 pp., Cambridge Univ. Press, New York.

Jordan, R. (1991), A one-dimensional temperature model for a snow cover: Technical documentation for SNTHERM.89, Spec. Tech. Rep. 91-16, U.S. Army Cold Reg. Res. and Eng. Lab., Hanover, N. H.

Kaimal, J., and J. Finnigan (1994), Atmospheric boundary layer flows: Their structure and measurement, 289 pp., Oxford Univ. Press, New York.

Koivusalo, H. (2002), Process-oriented investigation of snow accumulation, snowmelt and runoff generation in forested sites in Finland, Ph.D. dissertation, Helsinki Univ. of Technology, Helsinki, Finland.

Leuning, R. A. Y., and M. J. Judd (1996), The relative merits of open- and closed-path analysers for measurement of eddy fluxes, Global Change Biol., 2(3), 241-253, doi:10.1111/j.1365-2486.1996.tb00076.x.

Link, T., and D. Marks (1999), Distributed simulation of snowcover massand energy-balance in the boreal forest, Hydrol. Processes, 13, 24392452.

Lowe, P. R. (1977), An approximating polynomial for the computation of saturation vapour pressure, J. Appl. Meteorol., 16, 100-103.

Luce, C. H., and D. G. Tarboton (2010), Evaluation of alternative formulae for calculation for surface temperature in snowmelt models using frequency analysis of temperature observations, Hydrol. Earth Syst. Sci., $14,535-543$.

Lundberg, A., and S. Halldin (1994), Evaporation of intercepted snow: Analysis of governing factors, Water Resour. Res., 30(9), 2587-2598.

Lundberg, A., I. Calder, and R. Harding (1998), Evaporation of intercepted snow: Measurement and modelling, J. Hydrol., 206, 151-163.

Mahat, V. (2011), Effect of vegetation on the accumulation and melting of snow at the TW Daniels Experimental Forest, Ph.D. dissertation, 181 pp., Utah State Univ., Logan, UT. [Available at http://digitalcommons. usu.edu/etd/1078.]

Mahat, V., and D. G. Tarboton (2012), Canopy radiation transmission for an energy balance snowmelt model, Water Resour. Res., 48, W01534, doi : 10.1029/2011WR010438.

Marks, D. (1988), Climate, energy exchange, and snowmelt in Emerald lake watershed, Sierra Nevada, Ph.D. dissertation, Univ. of Calif., Santa Barbara. 
Marks, D., M. Reba, J. Pomeroy, T. Link, A. Winstral, G. Flerchinger, and K. Elder (2008), Comparing simulated and measured sensible and latent heat fluxes over snow under a pine canopy to improve an energy balance snowmelt model, J. Hydrometeorol., 9(6), 1505-1522, doi:10.1175/ 2008JHM874.1.

Massman, W. J. (1982), Foliage distribution in old-growth coniferous tree canopies, Can. J. For. Res., 12(1), 10-17.

Meyers, T. P., P. Finkelstein, J. Clarke, T. G. Ellestad, and P. F. Sims (1998), A multilayer model for inferring dry deposition using standard meteorological measurements, J. Geophys. Res., 103(D17), 2264522661.

Molotch, N. P., P. D. Blanken, M. W. Williams, A. A. Turnipsesd, R. K. Monson, and S. A. Marguilis (2007), Estimating sublimation of intercepted and sub-canopy snow using eddy covariance system, Hydrol. Processes, 21(12), 1567-1575.

Monteith, J. L., and M. H. Unsworth (1990), Principles of Environmental Physics, 2nd ed., 291 pp., Edward Arnold, London, U. K.

Nakai, Y., T. Sakamoto, T. Terajima, K. Kitamura, and T. Shirai (1999), The effect of canopy-snow on the energy balance above a coniferous forest, Hydrol. Processes, 13, 2371-2382.

Norman, J. M., W. P. Kustas, and K. S. Humes (1995), Source approach for estimating soil and vegetation energy fluxes in observations of directional radiometric surface temperature, Agric. For. Meteorol., 77(3-4), 263-293, doi:10.1016/0168-1923(95)02265-y.

Parviainen, J., and J. W. Pomeroy (2000), Multiple-scale modelling of forest snow sublimation: Initial findings, Hydrol. Processes, 14(15), 26692681.

Pearson, D., C. C. Daamen, R. J. Gurney, and L. P. Simmonds (1999), Combined modelling of shortwave and thermal radiation for one-dimensional SVATs, Hydrol. Earth Syst. Sci., 3(1), 15-30.

Price, A. G. (1988), Prediction of snowmelt rates in a deciduous forest, $J$. Hydrol., 101, 145-157.

Price, A. J., T. Dunne, and S. C. Colbeck (1976), Energy balance and runoff from a subarctic snowpack, CRREL Rep. 76-27, U.S. Army Corps or Eng., Cold Reg. Res. and Eng. Lab., Hanover, N. H.

Reba, M. L., T. E. Link, D. Marks, and J. Pomeroy (2009), An assessment of corrections for eddy covariance measured turbulent fluxes over snow in mountain environments, Water Resour. Res., 45, W00D38, doi: 10.1029/2008WR007045.

Richardson, A. D., M. Aubinet, A. G. Barr, D. Y. Hollinger, A. Ibrom, G. Lasslop, and M. Reichstein (2012), Uncertainty quantification, in Eddy Covariance, edited by M. Aubinet, T. Vesala, and D. Papale, pp. 173209, Springer, Netherlands.

Running, S. W., R. R. Nemani, D. L. Peterson, L. E. Band, D. F. Potts, L. L. Pierce, and M. A. Spanner (1989), Mapping regional forest evapotranspiration and photosynthesis by coupling satellite data with ecosystem simulation, Ecology, 70(4), 1090-1101.

Schotanus, P., F. T. M. Nieuwstadt, and H. A. R. Bruin (1983), Temperature measurement with a sonic anemometer and its application to heat and moisture fluxes, Boundary Layer Meteorol., 26(1), 81-93, doi:10.1007/ bf00164332.

Sellers, P. J., Y. Mintz, Y. C. Sud, and A. Dalcher (1986), A simple biosphere model $(\mathrm{SiB})$ for use with general circulation models, J. Atmos. Sci., 43(6), 505-531.

Shaw, R. H., and A. R. Periera (1982), Aerodynamic roughness of a plant canopy: A numerical experiment, Agric. Meteorol., 26, 51-65.

Shuttleworth, W. J. (1993), Evaporation, in Handbook of Hydrology, edited by D. R. Maidment, pp. 4.1-4.53, McGraw-Hill, New York.

Shuttleworth, W. J., and R. J. Gurney (1990), The theoretical relationship between foliage temperature and canopy resistance in sparse crops, $Q . J$. Roy. Meteorol. Soc., 116, 497-519.
Shuttleworth, W. J., and J. S. Wallace (1985), Evaporation from sparse crops-An energy combination theory, Q. J. Roy. Meteorol. Soc., 111, $839-855$.

Storck, P. (2000), Trees, Snow and Flooding: An Investigation of Forest Canopy Effects on Snow Accumulation and Melt at the Plot and Watershed Scales in the Pacific Northwest, 176 pp., Dep. of Civ. and Environ. Eng., Univ. of Wash., Seattle, Wash.

Storck, P., D. P. Lettenmaier, and S. M. Bolton (2002), Measurement of snow interception and canopy effects on snow accumulation and melt in a mountainous maritime climate, Oregon, United States, Water Resour. Res., 38(11), 1223, doi:10.1029/2002WR001281.

Suzuki, K., and Y. Nakai (2008), Canopy snow influence on water and energy balances in a coniferous forest plantation in northern Japan, $J$. Hydrol., 352(1-2), 126-138, doi:10.1016/j.jhydrol.2008.01.007.

Tarboton, D. G., and C. H. Luce (1996), Utah energy balance snow accumulation and melt model (UEB), in Computer Model Technical Description and Users Guide, Utah Water Res. Lab. and USDA For. Serv. Intermountain Res. Stn. [Available at http://www.engineering.usu.edu/ dtarb/.].

Tarboton, D. G., T. G. Chowdhury, and T. H. Jackson (1995), A spatially distributed energy balance snowmelt model, in Biogeochemistry of Seasonally Snow-Covered Catchments, edited by K. A. Tonnessen, M. W. Williams, and M. Tranter, Proceedings of a Boulder Symposium, IAHS Publ. 228 pp., 3-14 July. [Available at http://iahs.info/redbooks/ a228/iahs_228_0141.pdf.]

Tribbeck, M. J., R. J. Gurney, E. M. Morris, and D. W. C. Pearson (2004), A new Snow-SVAT to simulate the accumulation and ablation of seasonal snow cover beneath a forest canopy, J. Glaciol., 50, 171-182, doi: $10.3189 / 172756504781830187$.

Turnipseed, A. A., P. D. Blanken, D. E. Anderson, and R. K. Monson (2002), Energy budget above a high-elevation subalpine forest in complex topography, Agric. For. Meteorol., 110(3), 177-201, doi:10.1016/ s0168-1923(01)00290-8.

Turnipseed, A. A., D. E. Anderson, P. D. Blanken, W. M. Baugh, and R. K. Monson (2003), Airflows and turbulent flux measurements in mountainous terrain: Part 1. Canopy and local effects, Agric. For. Meteorol., 119(1-2), 1-21, doi:10.1016/s0168-1923(03)00136-9.

U.S. Army Corps of Engineers (1956), Snow Hydrology, Summary Report of the Snow Investigations, U.S. Army Corps of Eng., North Pacific Div., Portland, Oreg.

Webb, E. K., G. I. Pearman, and R. Leuning (1980), Correction of flux measurements for density effects due to heat and water vapour transfer, Q. J. Roy. Meteorol. Soc., 106(447), 85-100, doi:10.1002/ qj. 49710644707.

Wigmosta, M. S., L. W. Vail, and D. P. Lettenmaier (1994), A distributed hydrology-vegetation model for complex terrain, Water Resour. Res., 30(6), 1665-1679.

Wigmosta, M. S., B. Nijssen, and P. Storck (2002), The distributed hydrology soil vegetation model, in Mathematical Models of Small Watershed Hydrology and Applications, edited by V. P. Singh and D. K. Frevert, pp. 7-42, Water Resour. Publ., Highlands Ranch, Colo.

Yang, D., B. E. Goodison, J. R. Metcalfe, V. S. Golubev, R. Bates, T. Pangburn, and C. L. Hanson (1998), Accuracy of NWS 8" standard nonrecording precipitation gauge: Results and application of WMO intercomparison, J. Atmos. Oceanic Technol., 15(1), 54-68, 10.1175/ 1520-0426(1998)015<0054:aonsnp $>2.0$. co; 2 .

You, J. (2004), Snow hydrology: The parameterization of subgrid processes within a physically based snow energy and mass balance model, Ph.D. dissertation, Utah State Univ., Logan, Utah.

Zheng, G., and L. M. Moskal (2009), Retrieving leaf area index (LAI) using remote sensing: Theories, methods and sensors, Sensors, 9(4), 27192745 . 